\title{
ESTRUTURA DA GUILDA DE ABELHAS VISITANTES DE Matayba guianensis AUBL. (SAPINDACEAE) EM VEGETAÇÃO DO CERRADO
}

\author{
Ana Maria Coelho Carvalho ${ }^{1, *} \&$ Paulo Eugênio Alves Macedo de Oliveira ${ }^{1}$ \\ ${ }^{1}$ Instituto de Biociências, Universidade Federal de Uberlândia. Rua Duque de Caxias, 285. Caixa Postal: 593. Uberlândia, MG, Brasil. \\ CEP: 38400-902. \\ E-mails: anacoelhocarvalho@terra.com.br, poliveira@ufu.br
}

\section{RESUMO}

A estrutura da guilda de abelhas visitantes de plantas envolve fatores diversificados, tais como a morfologia, tipo de recompensa e mesmo densidade dos recursos florais. Mas seu estudo permite o entendimento de vários aspectos da interação abelha-planta. Matayba guianensis Aubl. (Sapindaceae), é uma planta comum nos cerrados e que apresenta morfologia floral generalista, atraindo uma ampla diversidade de insetos, O objetivo do presente trabalho foi verificar a estrutura da guilda de abelhas visitantes dessa planta, abordando a riqueza e abundância das espécies e padrões de forrageamento. Os visitantes florais foram acompanhados em 2005 e 2006, na época de sua floração, de outubro a dezembro, em três áreas de cerrado com diferentes tamanhos e com menor ou maior cobertura de vegetação natural. As abelhas foram coletadas quinzenalmente, com rede entomológica, por dois coletores. Foram seis coletas, em 2005, com oito horas diárias, e cinco coletas, em 2006, de quatro horas diárias. Na primeira etapa foram capturadas 1516 abelhas pertencentes a 80 espécies, sendo 24 dominantes (30\%). Na segunda etapa foram coletados 562 indivíduos de 66 espécies, sendo dez dominantes (15\%). As abelhas pertenciam a cinco famílias de Apoidea, totalizando 105 espécies e 2078 indivíduos. Apidae foi a família melhor representada em número de espécies e em número de indivíduos. A grande dominância de Apidae em número de indivíduos ocorreu principalmente devido a duas espécies eussociais, Apis mellifera e Scaptotrigona depilis. Outras espécies abundantes foram Rophitulus sp., Tetragonisca angustula e Scaptotrigona polysticta. Apis mellifera predominou nas três áreas. As espécies mais abundantes de abelhas apresentaram picos de atividade não coincidentes, mas não houve um padrão de forrageamento de divisão de recursos. $\mathrm{O}$ padrão encontrado na guilda de abelhas visitantes de Matayba guianensis foi condizente com o padrão geral de dominância de Apidae em ambiente de cerrado. Na distribuição de espécies, houve um pequeno número de espécies com grande abundância de indivíduos, ao lado de um grande número de espécies raras, com poucos indivíduos.

Palavras-chave: Apoidea; riqueza; abundância; espécies dominantes e raras; forrageamento.

\begin{abstract}
GUILD STRUCTURE OF BEES VISITING Matayba guianensis AUBL. (SAPINDACEAE) IN CERRADO VEGETATION. The guild structure of bees which visit plants involve varied aspects, such as morphology, recompense type, and even floral resource density. Their study allows the understanding of many aspects related to bee-plant interaction. Matayba guianensis Aubl. (Sapindaceae) is a common plant in cerrado and present a generalist floral morphology, attracting a wide range diversity of insects. The objective of the present work was to verify the guild structure of bees that visit this plant, studying the richness and abundance of species and foraging patterns. The floral visitors were accompanied in 2005 and 2006, during the flowering period, from October to December, in three areas of the cerrado with different sizes and with lower or higher natural vegetation covering. Bees were collected fortnightly, with entomological net, by two collectors. Six samples were carried out in 2005 during 8 hours a day, and five samples were carried out in 2006 during 4 hours
\end{abstract}


a day. In the first stage 1,516 bees from 80 species were sampled, with the dominance of 24 species (30\%). In the second stage 562 individuals from 66 species were sampled, with the dominance of 10 species (15\%). Bees were from five Apoidea families, in a total of 105 species and 2078 individuals. Apidae was the most common family both in number of species and number of individuals. The predominance of Apidae in relation to the number of individuals occurred mainly due to two eusocial species, Apis mellifera and Scaptotrigona depilis. Other abundant species were Rophitulus sp., Tetragonisca angustula and Scaptotrigona polysticta. Apis mellifera was predominant on the three sampled areas. The most abundant bee species presented noncoincidental activity peaks, but there was not a foraging pattern of resource division. The pattern found on the guild structure of bees which visit Matayba guianensis was in accordance with the general pattern related to the dominance of Apidae on the Cerrado environment. In relation to species distribution, there was a small number of species with great abundance of individuals, and a great number of rare species with few individuals.

Keywords: Apoidea; richness; abundance; rare and dominant species; foraging.

\section{RESUMEN}

ESTRUCTURA DEL GREMIO DE ABEJAS VISITANTES DE Matayba guianensis AUBL. (SAPINDACEAE) EN VEGETACIÓN DE CERRADO. La estructura del gremio de abejas visitantes de plantas involucra factores diversificados, tales como la morfología, el tipo de recompensa y la densidad de los recursos florales. Sin embargo, su estudio permite el entendimiento de varios aspectos de la interacción abejaplanta. Matayba guianensis Aubl. (Sapindaceae), es una planta común en los cerrados, que presenta morfología floral generalista, atrayendo una amplia diversidad de insectos. El objetivo del presente trabajo fue verificar la estructura del gremio de abejas visitantes de esta planta, abordando la riqueza y abundancia de las especies y patrones de forrajeo. Los visitantes florales fueron acompañados en 2005 y 2006, en la época de su floración, de octubre a diciembre, en tres áreas de cerrado con diferentes tamaños y con menor o mayor cobertura de vegetación natural. Las abejas fueron colectadas quincenalmente, con red entomológica, por dos colectores. Fueron seis colectas, en 2005, con ocho horas diarias, y cinco colectas en 2006, de cuatro horas diarias. En la primera etapa fueron capturadas 1516 abejas pertenecientes a 80 especies, siendo 24 dominantes (30\%). En la segunda etapa fueron colectados 562 individuos de 66 especies, siendo diez dominantes (15\%). Las abejas pertenecieron a cinco familias de Apoidea, totalizando 105 especies y 2078 individuos. Apidae fue la familia mejor representada en número de especies y en número de individuos. La gran dominancia de Apidae en número de individuos ocurrió principalmente debido a dos especies eusociales, Apis mellifera y Scaptotrigona depilis. Otras especies abundantes fueron Rophitulus sp., Tetragonisca angustula y Scaptotrigona polysticta. Apis mellifera predominó en las tres áreas. Las especies más abundantes de abejas presentaron picos de actividad no coincidentes, pero no hubo un patrón de forrajeo de división de recursos. El patrón encontrado en el gremio de abejas visitantes de Matayba guianensis fue coincidente con el patrón general de predominancia de Apidae en ambientes de cerrado. En la distribución de especies, hubo un pequeño número de especies con gran abundancia de individuos, al lado de un gran número de especies raras, con pocos individuos.

Palabras clave: Apoidea; riqueza; abundancia; especies dominantes y raras; forrajeo.

\section{INTRODUÇÃO}

O estudo da estrutura da guilda de abelhas visitantes de flores envolve aspectos complexos e diversificados. Para um melhor entendimento desses aspectos, existem muitos estudos, com diferentes objetivos e múltiplos enfoques sobre a interação abelha-planta. Estes dados têm sido revisados em análises complexas, como a de Williams et al. (2001), onde os autores compararam 47 estudos realizados em diferentes partes do mundo, em três décadas.

No Brasil, o número de espécies de abelhas obtido em levantamentos com ao menos um ano de coleta, é freqüentemente superior a 100 (Pinheiro-Machado et al. 2002). No entanto, é difícil especificar locais com maior riqueza de espécies, porque existem diferenças na metodologia e no esforço de coleta (PinheiroMachado et al. 2002, Williams et al. 2001). Além 
disso, a estrutura da guilda ou da comunidade parece ser estreitamente associada com o tipo de vegetação de um dado local (Harter et al. 2002).

No cerrado, por exemplo, nos levantamentos realizados em Minas Gerais e São Paulo, foram encontradas de 103 a 140 espécies de abelhas, visitando de 75 a 184 espécies de plantas (Andena et al. 2005). Nessas associações, a família Apidae sempre se sobressai em número de espécies e de indivíduos. Dentre as plantas visitadas, algumas famílias têm se destacado como fonte de recursos para as abelhas nesse tipo de vegetação, como Asteraceae, Malpighiaceae e Vochysiaceae (Silveira 1989, Silveira \& Campos 1995, Carvalho \& Bego 1996, Andena et al. 2005, Araújo et al. 2006). Algumas plantas específicas também se destacam, sendo bastante atrativas e generalistas quanto a seus visitantes, como Matayba guianensis Aubl., uma Sapindaceae comum no cerrado, em cujas flores foram registradas 29 espécies de abelhas, na Estação Ecológica do Panga (Carvalho \& Bego 1997). Tais espécies de plantas podem funcionar como espécieschave, atraindo parcelas expressivas das espécies de abelhas presentes numa dada região, mantendo populações de abelhas e possivelmente amenizando o impacto dos processos de degradação (Macedo \& Martins 1999, Minkley et al. 1999, Moeller 2004, Ramalho \& Silva 2002). Estas espécies podem funcionar ainda como indicadores biológicos, sendo que o universo de abelhas visitantes, nestes casos, é pouco afetado por mudanças florísticas ocorrendo de área para área.

Estudos no cerrado são importantes para subsidiar programas de manejo e conservação, pois no atual ritmo de degradação do bioma, é possível que muitas espécies de abelhas entrem em processo de extinção, nos próximos anos, sem ao menos terem sido descobertas. No caso específico do município de Uberlândia, 92,4\% do solo está ocupado por áreas de pastagens e cultivo, sendo que as frações de cerrado que sobraram constituem reservas legais pertencentes a propriedades particulares (Araújo 2006). Na avaliação das guildas de abelhas, é importante, então, o uso de plantas focais capazes de crescer igualmente nestas áreas mais conservadas e nas áreas degradadas pela ação antrópica.

Além do enfoque na necessidade de conhecimento e conservação das espécies de abelhas do cerrado, o estudo da estrutura de guilda de abelhas visitantes de plantas permite enfocar aspectos fascinantes da ecologia, como partição de recursos e competição (Johnson \& Hubbel 1974, Biesmeijer et al. 1999, El Shafie \& Mogga 2002, Dutra \& Machado 2001, Morgado et al. 2002, Aguiar et al. 2002, Dupont et al. 2004). Por exemplo, a separação de espécies em nichos, envolvendo dimensões como habitat, nutrientes e tempo, diminui a sobreposição no uso dos recursos, o que pode diminuir a competição e aumentar a coexistência entre espécies (Jones et al. 2001).

Outro aspecto importante no estudo da estrutura de guildas é a possibilidade de entendimento da dinâmica das comunidades e guildas de abelhas. Segundo Williams et al. (2001), essas são dinâmicas ao longo do tempo e do espaço, apresentando uma grande variação, mesmo em sítios próximos e dentro do mesmo período. De acordo com Antonini \& Martins (2003) essas alterações são causadas por muitos fatores ecológicos e históricos, tais como disponibilidade de locais para ninhos, competição pelo alimento e distribuição geográfica de cada grupo.

$\mathrm{O}$ presente trabalho visou então determinar a estrutura da guilda de abelhas visitantes de $M$. guianensis, abordando-se a riqueza e abundância das espécies de abelhas em diferentes áreas e avaliando as possíveis sobreposição ou competição no uso dos recursos florais.

\section{MATERIAL E MÉTODOS}

\section{ÁREA DE ESTUDO}

O estudo foi desenvolvido na região do Triângulo Mineiro, localizado a oeste de $\mathrm{MG}$, entre as coordenadas $47^{\circ} 00^{\prime}-51^{\circ} 00^{\prime} \mathrm{O}$ e $18^{\circ} 30^{\prime}-20^{\circ} 30^{\prime} \mathrm{S}$. O clima do município de Uberlândia apresenta duas estações bem definidas: uma seca, com período de estiagem de maio a agosto e outra úmida, de novembro a março. A precipitação pluviométrica é de $1600 \mathrm{~mm}$ anuais, sendo maior em dezembro e janeiro (Rosa et al. 1991).

Foram selecionadas três áreas de cerrado (Figura 1), dentre os fragmentos de cerrado existentes na zona urbana e na zona rural próximas à cidade. As áreas escolhidas apresentavam vegetação relativamente bem conservada e adequada representatividade da 
planta focal. A descrição das áreas encontra-se a seguir.

\section{Estação Ecológica do Panga - EEP}

Compreende uma área de 403,85ha, pertencente à Universidade Federal de Uberlândia. Situa-se aproximadamente a $30 \mathrm{~km}$ ao sul de Uberlândia. Sua posição geográfica compreende as coordenadas $19^{\circ} 09^{\prime} 20^{\prime \prime}-19^{\circ} 11^{\prime} 10^{\prime}$ " S e 48 23'20"-48 $24^{\circ} 35^{\circ}$ " O, a uma altitude média de $800 \mathrm{~m}$; o solo varia de latossolo vermelho a latossolo vermelho-amarelado, profundos e bem drenados, a solos hidromórficos, mal drenados (Schiavini \& Araújo 1989)

Quanto à vegetação, a EEP possui representatividade dos diversos tipos fitofisionômicos do bioma Cerrado, sendo uma das poucas áreas naturais bem conservadas do município e pouco sujeita a ações antrópicas. Schiavini \& Araújo (1989) descreveram seus tipos florestais, como mata mesofítica e mata xeromórfica; tipos savânicos, como cerrado, campo cerrado e campo sujo; tipos campestres, como campos úmidos e veredas. Em julho de 2006, parte da reserva foi queimada por um incêndio acidental.

\section{Cerrado na Fazenda Palma da Babilônia - FPB}

O cerrado amostrado possui cerca de 180ha. Localiza-se em duas fazendas vizinhas (propriedades particulares), fazenda Palma da Babilônia, com aproximadamente 100ha e fazenda Campo Alegre, com cerca de 300 ha. Localizam-se às margens da BR 497, coordenadas $19^{\circ} 02^{\prime} 41,8^{\prime \prime} \mathrm{S}$ e $48^{\circ} 32^{\prime}$ '59,9' O.

$\mathrm{O}$ cerrado sentido restrito localiza-se de forma descontínua, sendo recortado por estradas, casas, pastagens e seringal. É circundado por áreas de pastagens e de cultura, sofrendo forte ação antrópica devido à criação de gado e extração de borracha. No primeiro semestre de 2006, parte do mesmo foi desmatada para pastagem, sendo instalada uma carvoaria no local.

\section{Reserva na Souza Cruz - SC}

$\mathrm{Na}$ zona urbana de Uberlândia encontram-se alguns fragmentos de cerrado conservados, como os existentes no Distrito Industrial.Um desses fragmentos é a reserva localizada dentro da fábrica Souza Cruz, escolhido para o estudo, com as coordenadas geográficas $18^{\circ} 52^{\prime} 10,82^{\prime \prime} \mathrm{S}$ e $48^{\circ} 18^{\prime} 16,46^{\prime \prime} \mathrm{O}$ e com 40ha.

O cerrado localiza-se no interior da área da SC, sendo recortado por estradas e trilhas e separado por prédios em dois fragmentos menores. Sofre ação antrópica, com pessoas e veículos que transitam no local, com o barulho da fábrica e com o intenso trânsito de veículos nas proximidades. A vegetação é de cerrado sentido restrito, com plantas típicas da região.

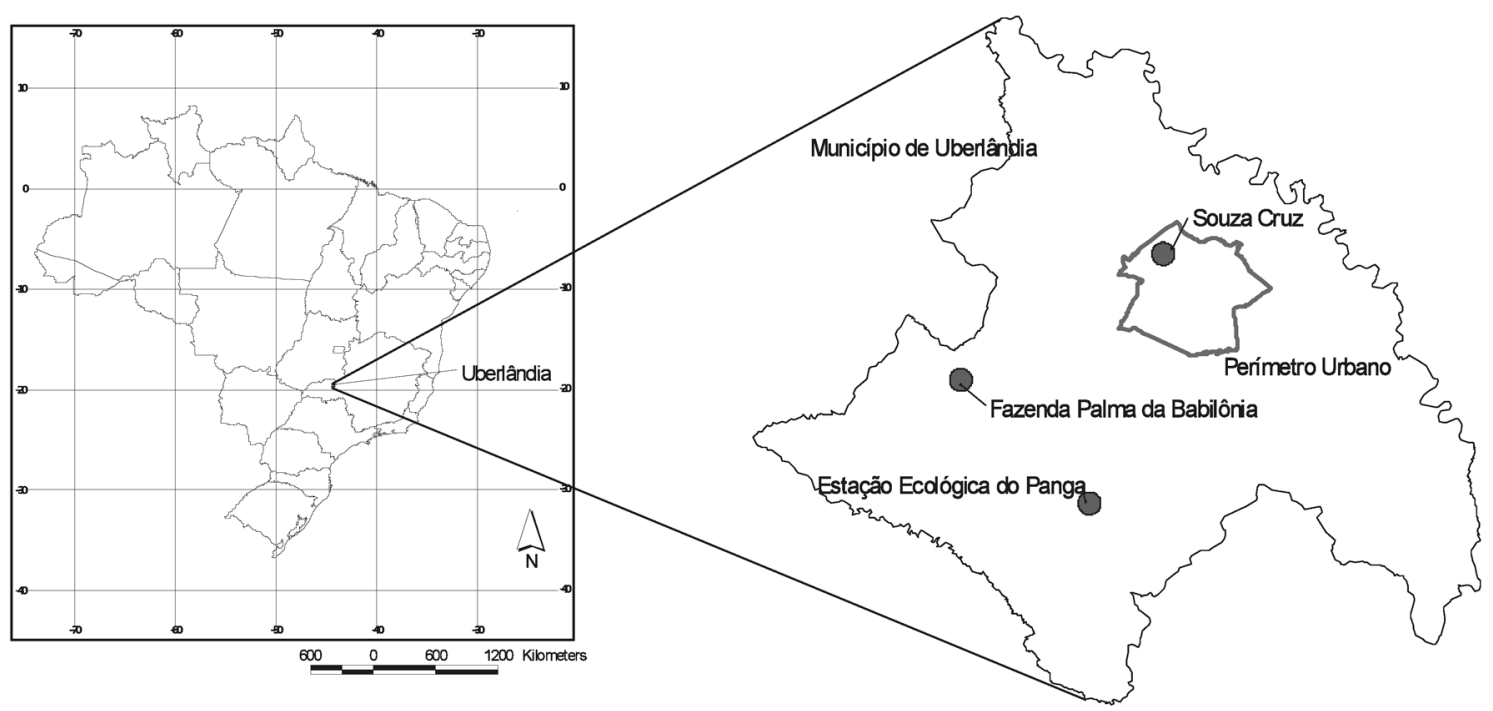

Figura 1. Localização das áreas de estudo em cerrados no município de Uberlândia, MG

Figure 1. Study areas of cerrado vegetation at Uberlandia municipality, Minas Gerais. 
COBERTURA DE VEGETAÇÃO NATURAL EM

\section{CADA AREA}

Para calcular a porcentagem de vegetação natural em cada área, utilizaram-se recursos do Google Earth e imagens por satélite (Yamamoto 2009). Determinouse um ponto central em cada área e demarcou-se um entorno de dois $\mathrm{km}$ em volta do mesmo, originando assim um círculo com cerca de 1000 ha em cada uma das três áreas estudadas. Esta área demarcada foi quadriculada e em cada quadrícula foi definida se havia ou não vegetação de cerrado. $\mathrm{O}$ somatório das quadrículas foi utilizado para calcular a área de distribuição da cobertura natural. No entorno da EEP, a área com vegetação de cerrado era de 551ha $(52,62 \%)$ e de área antropizada, 496ha (47,38\%). No

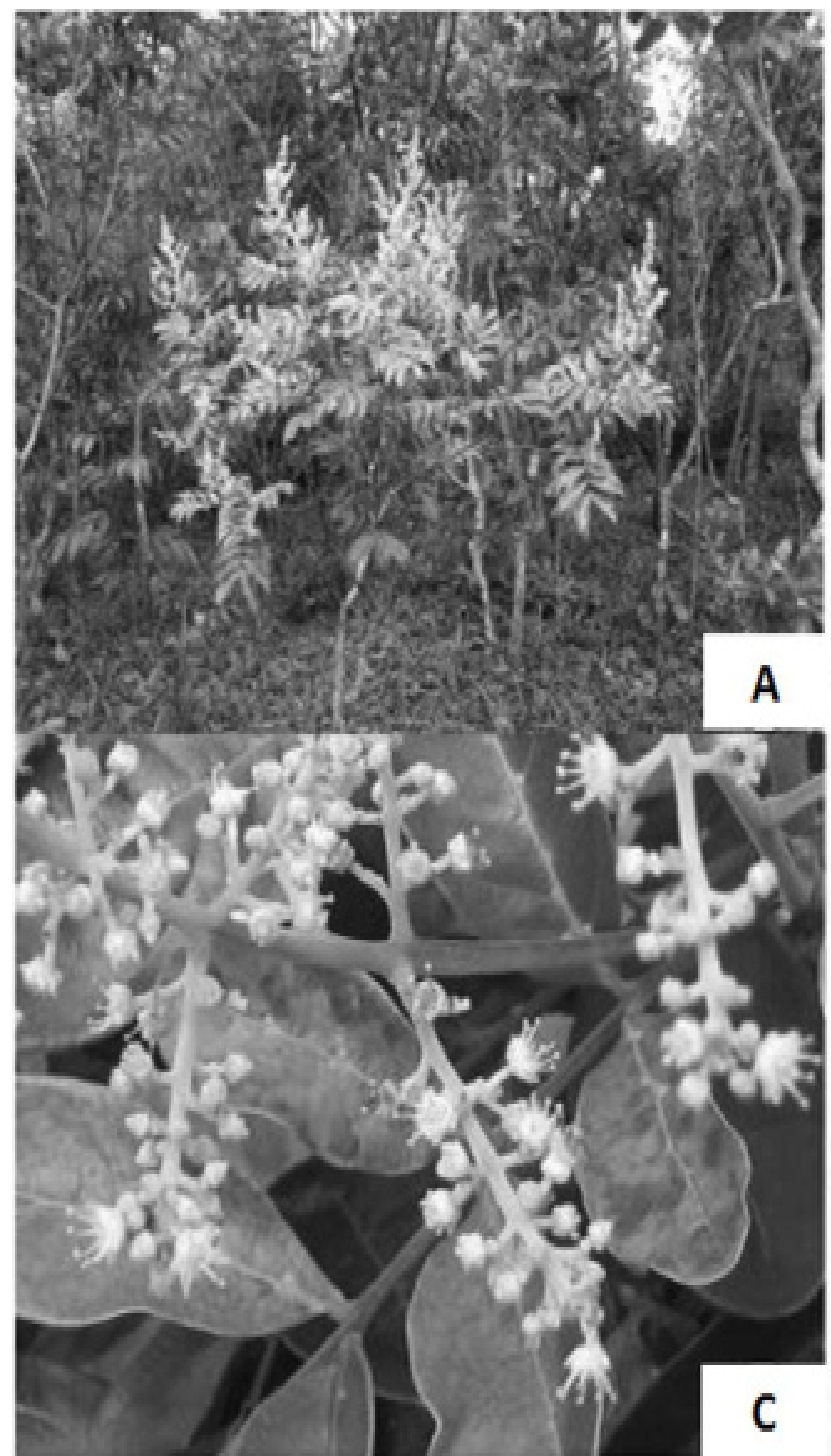

entorno da FPB, a área com vegetação de cerrado era de 341ha (32,94\%) e a área antropizada, de 694ha $(67,06 \%)$. Na SC, a área com vegetação de cerrado era de apenas 103 ha $(9,73 \%)$ enquanto a área antropizada possuia 955 ha $(90,27 \%)$.

\section{PLANTA FOCAL: Matayba guianensis}

Entre as várias plantas do cerrado, escolheu-se M. guianensis Aubl. (Sapindaceae) (Figura 2) por ser comum no cerrado e possuir populações amplas nas três áreas escolhidas. Além disto, é bastante atrativa para as abelhas (Carvalho \& Bego 1996).

Matayba guianensis é originária do planalto setentrional da América do Sul; pertence à subtribo Cupaniae e seção Eumatayba, família Sapindaceae.

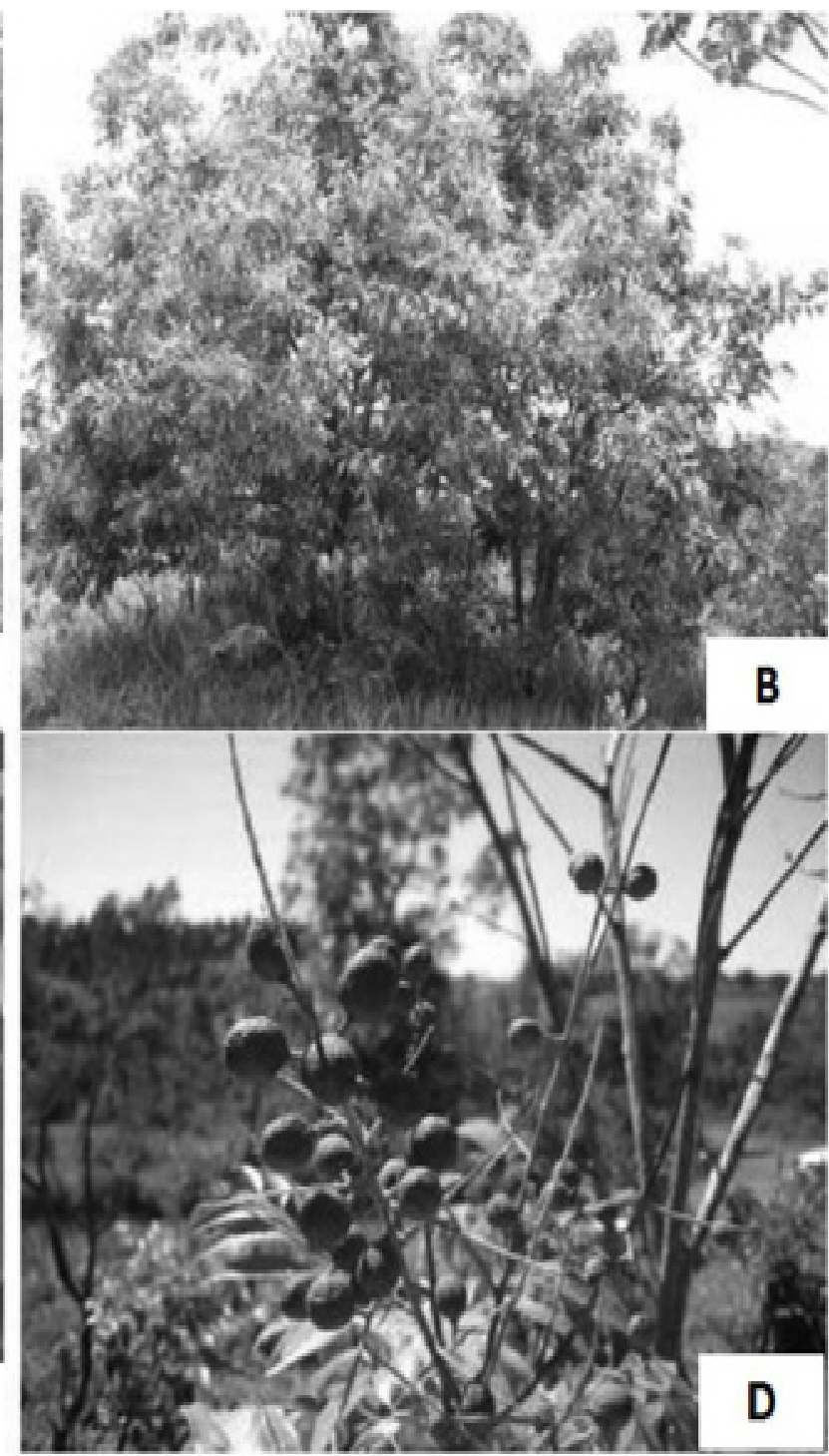

Figura 2. Planta focal Matayba guianensis em áreas de cerrado no município de Uberlândia, MG: A) arbusto; B) árvore; C) botões e flores; D) frutos maduros.

Figure 2. The focal plant Matayba guianensis in cerrado vegetation areas at Uberlandia municipality, Minas Gerais: A) shrub; B) tree; C) buds and flowers; D) ripe fruits. 
Vulgarmente é denominada camboatá, pindaíba ou mataíba. Apresenta forte variação fenotípica, de arbustos pequenos até árvores muito altas, em áreas de mata e cerradão, com 10 a $25 \mathrm{~m}$ de altura, com inflorescência em panículas axilares, flores brancas ou verde-amareladas (Figura 2). Floresce nos meses de outubro, novembro e dezembro e frutifica nos meses de novembro, dezembro e janeiro (Reitz 1980, Mantovani et al. 2003).

Matayba guianensis tem se destacado na composição de reflorestamentos mistos destinados ao repovoamento de áreas degradadas de preservação permanente e tem grande importância fitossociológica nos cerrados da região (Oliveira et al. 2003). M. guianensis e Xylopia sp. são as plantas que ocorrem com maiores populações em áreas de cerrado degradado, podendo ser utilizadas como plantas indicadoras de ambientes alterados (Araújo et al. 1997). Além disto, M. guianensis pode apresentar propagação vegetativa (Fernandes 2005), o que acarreta a concentração de indivíduos em determinadas áreas.

As flores de $M$. guianensis são de três tipos (polimorfismo floral): tipo pistilado, funcionalmente feminina e com anteras indeiscentes, e dois tipos estaminados, ambos com estigma não funcional e que diferem no tamanho do estilete (curto sem estigma evidente e médio com estigma pouco evidente); as flores estaminadas produzem néctar e pólen e as pistiladas, apenas néctar (Martins 2002). No campo, mostrou-se difícil o reconhecimento das diferenças entre os tipos de flores estaminadas. Assim, as flores masculinas/estaminadas foram consideradas como apenas um tipo. Todos os tipos florais produzem pequenas quantidades de néctar com baixas concentrações de açúcares (Martins 2002). Quanto ao sistema reprodutivo, há indivíduos com flores pistiladas, indivíduos com flores estaminadas e indivíduos com flores pistiladas e estaminadas, ou seja, a planta é trióica, sendo a espécie funcionalmente monóica e autocompatível (Martins 2002).

\section{COLETA DE ABELHAS}

As coletas de abelhas foram realizadas no período de floração de M. guianensis, em duas floradas consecutivas, de outubro de 2005 a janeiro de 2006 (primeira etapa) e de outubro de 2006 a dezembro de
2006 (segunda etapa). As coletas iniciaram quando começaram a surgir flores atrativas nas três áreas e terminaram no final da floração da espécie.

O método de coleta foi o da "varredura" das plantas com flores, com rede entomológica, conforme Sakagami et al. (1967). As abelhas foram coletadas quinzenalmente por dois coletores, sobre as flores e até a altura alcançada com o braço. No caso de Apis mellifera, quando a planta estava muito atrativa para estas abelhas, não foram coletados todos os exemplares observados.

Em cada uma das três áreas de estudo foram definidos cinco locais para a coleta das abelhas e cada local era percorrido uma única vez. Em alguns existiam trilhas e as abelhas eram coletadas ao longo das mesmas. Em outros, os indivíduos de M. guianensis encontravam-se mais agrupados e as coletas eram realizadas caminhando-se entre eles. O número de plantas de $M$. guianensis em cada local era bastante variado, de cinco a cerca de 30 a 40 indivíduos.

Na primeira etapa, as coletas tiveram duração de oito horas, de $8 \mathrm{~h}$ às $16 \mathrm{~h}$, totalizando seis coletas em cada área e 138h. As horas de coleta foram distribuídas equitativamente entre cada um dos cinco locais, ou seja, os coletores percorriam cada local por cerca de $1 \mathrm{~h}$ e $20 \mathrm{~min}$.

$\mathrm{Na}$ segunda etapa, as coletas tiveram duração de quatro horas, de $9 \mathrm{~h}$ às $13 \mathrm{~h}$, totalizando cinco coletas em cada área e $60 \mathrm{~h}$. O número de coletas foi menor em relação à primeira etapa porque o período de floração de $M$. guianensis terminou mais cedo em 2006. No acompanhamento da segunda floração, foram coletadas abelhas nas mesmas plantas ou em plantas diferentes das amostradas na primeira floração. Com a finalidade de verificar sobreposição no uso de recursos, foram marcadas e numeradas 17 plantas de $M$. guianensis, em cada uma das três áreas amostradas, nas quais verificou-se a existência ou não de abelhas visitando uma mesma planta no mesmo horário. $\mathrm{O}$ horário de coleta na segunda etapa foi reduzido porque pretendia-se coletar abelhas no horário de maior atividade das mesmas. Além disto, alguns locais foram alterados de um ano para o outro.

O tempo de coleta a cada dia foi dividido em intervalos de uma hora, para posterior análise do horário de forrageamento das espécies como um todo 
e, em particular, das espécies mais abundantes. Nessa análise foi considerado como pico de visitação o horário em que foi coletado maior número de abelhas daquela espécie.

Os exemplares de abelhas capturados foram colocados em frascos mortíferos com acetato de etila e etiquetados de acordo com local, coletor, data e horário da coleta. As abelhas coletadas nos indivíduos marcados de $M$. guianensis eram acondicionadas em frascos que continham também o número da planta. Os espécimes foram alfinetados, etiquetados e identificados por especialistas. De acordo com o sistema de classificação proposto por Silveira et al. (2002), foi montada uma coleção a seco, depositada no Laboratório de Insetos Sociais do Instituto de Biologia da UFU.

Ao longo das duas etapas da coleta, foram retirados ramos floridos de algumas plantas de espécies diferentes de $M$. guianensis, para posterior identificação de plantas que estavam floridas na área ao mesmo tempo em que a planta focal, e que poderiam também estar sendo visitadas por abelhas.

\section{ANÁLISE}

Para se determinar a estrutura da comunidade, foi analisada a riqueza da guilda de abelhas visitantes de $M$. guianensis, representada pelo número total de espécies coletadas e pelo número de espécies em cada uma das três áreas estudadas. Foram selecionadas as espécies dominantes de abelhas, isto é, aquelas coletadas em maior número, de acordo com método descrito por Kato et al. (1952).

Utilizou-se a seguinte fórmula para calcular a abundância relativa em termos de números de indivíduos e os limites de confiança:

Limite Superior:

$$
\frac{\mathrm{n}_{1} \mathrm{~F}_{0}}{\mathrm{n}_{2}+\mathrm{n}_{1} \mathrm{~F}_{0}} \times 100
$$

Sendo: $\mathrm{n}_{1}=2(\mathrm{~K}+1)$ e $\mathrm{n}_{2}=2(\mathrm{~N}-\mathrm{K}+1)$.

Limite Inferior:

$$
\left[1-\frac{n_{1} F_{0}}{n_{2}+n_{1} F_{0}}\right] \times 100
$$

Sendo: $\mathrm{n}_{1}=2(\mathrm{~N}-\mathrm{K}+1)$ e $\mathrm{n}_{2}=2(\mathrm{~K}+1)$, onde $\mathrm{N}$ é o número total de todas as abelhas capturadas e $\mathrm{K}$, o número de indivíduos de cada espécie. O Fo é determinado através da tabela de distribuição $\mathrm{F} 1$ nos graus de liberdade $n 1$ e $n 2(=0,05)$.

As espécies de abelhas dominantes apresentam limite de confiança inferior maior que o limite superior calculado para uma espécie hipotética que pode existir na área, mas que não foi capturada, tendo portanto $\mathrm{K}=0$ (Laroca 1974 citado em Campos 1989).

O teste de correlação de Pearson foi utilizado para verificar se a abundância de uma espécie de abelha tem relação com a abundância de outra espécie, ao longo do período de coleta e em uma mesma área de estudo.

\section{RESULTADOS}

\section{ABELHAS VISITANTES DE Matayba guianensis}

\section{Famílias, gêneros e espécies de Apoidea}

Nas três áreas amostradas, foi coletado um total de 2078 abelhas, pertencentes a cinco famílias, 42 gêneros e a 105 espécies, sendo 1516 indivíduos e 80 espécies coletados na primeira etapa e 562 indivíduos e 66 espécies coletados na segunda (Tabela 1).

A família melhor representada em número de espécies, nas duas etapas, foi Apidae. Na primeira etapa, com 40 espécies $(50,0 \%$ do total), seguida por Halictidae, com 20 espécies $(25,0 \%)$, Colletidae com 10 (12,5\%), Megachilidae com 9 (11,25\%) e Andrenidae com apenas uma espécie $(1,25 \%)$ (Tabelas 2 e 3).

$\mathrm{Na}$ segunda etapa, Apidae foi representada por 28 espécies (42,4\% do total), seguida por Halictidae, com 22 espécies (33,3\%), Colletidae com dez (15,2\%), Megachilidae com cinco (7,6\%) e Andrenidae com apenas uma espécie (1,5\%). A seqüência das famílias em número de espécies, na primeira e segunda etapas, foi idêntica: Apidae $>$ Halictidae $>$ Colletidae $>$ Megachilidae $>$ Andrenidae (Tabelas 2 e 3).

Quanto ao número de indivíduos, Apidae foi também a família melhor representada, tanto na primeira como na segunda etapas, com 1249 $(82,39 \%)$ e $432(76,9 \%)$ abelhas, respectivamente (Tabela 2). O grande número de abelhas nessa família ocorreu principalmente devido à abundância de duas 
Tabela 1. Número, sexo e ocorrência de abelhas visitantes de Matayba guianensis em cerrados do município de Uberlândia, MG. Outubro a dezembro/2005 ( $1^{\text {a }}$ etapa) e outubro a dezembro/2006 ( $2^{\mathrm{a}}$ etapa). 1: Estação Ecológica do Panga; 2: cerrado na Fazenda Palma da Babilônia; 3: reserva na Souza Cruz; T: total.

Table 1. Number, sex and occurrence of bee visitors of Matayba guianensis in cerrados of Uberlândia (Minas Gerais). October to December/2005 (1st stage) and October to December/2006 (2nd stage). 1: Estação Ecológica do Panga; 2: Cerrado at Fazenda Palma da Babilônia; 3: Souza Cruz Cerrado reserve; T: total.

\begin{tabular}{|c|c|c|c|c|c|c|c|c|}
\hline \multirow{2}{*}{$\begin{array}{l}\text { Família / Subfamília / Tribo } \\
\text { Espécie }\end{array}$} & \multicolumn{3}{|c|}{$1^{\mathrm{a}}$ etapa } & \multicolumn{3}{|c|}{$2^{\mathrm{a}}$ etapa } & \multicolumn{2}{|c|}{ Ocorrência } \\
\hline & 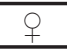 & d & $\mathrm{T}$ & $q$ & o & $\mathrm{T}$ & 2005 & 2006 \\
\hline \multicolumn{9}{|l|}{ Andrenidae / Panurginae / Protandrenini } \\
\hline Rophitulus sp. & 114 & 0 & 114 & 42 & 0 & 42 & $1,2,3$ & 1,2 \\
\hline \multicolumn{9}{|l|}{ Apidae / Apinae / Apini } \\
\hline Apis mellifera Linnaeus, 1758 & 635 & 0 & 635 & 183 & 0 & 183 & $1,2,3$ & $1,2,3$ \\
\hline Cephalotrigona capitata (Smith, 1854) & & & & 1 & 0 & 1 & & 2 \\
\hline Bombus atratus Franklin, 1913 & 4 & 3 & 7 & & & & $1,2,3$ & \\
\hline Eufrisea sp. & 0 & 1 & 1 & & & & 2 & \\
\hline Frieseomellita doederleini (Friese,1900) & 6 & 0 & 6 & & & & 1,2 & \\
\hline Geotrigona mombuca (Smith, 1863) & 2 & 4 & 6 & 4 & 0 & 4 & 3 & 1,2 \\
\hline Leurotrigona muelleri (Friese, 1900) & 2 & 0 & 2 & 1 & 0 & 1 & 2 & 1 \\
\hline Melipona quadrifasciata anthidioides Lepeletier, 1836 & 1 & 0 & 1 & & & & 1 & \\
\hline Melipona quinquefasciata Lepeletier, 1836 & 2 & 0 & 2 & 6 & 0 & 6 & 1,2 & 1,2 \\
\hline Melipona rufiventris Lepeletier, 1836 & 7 & 0 & 7 & 5 & 0 & 5 & 1,2 & 1,2 \\
\hline Nannotrigona testaceicornis (Lepeletier, 1836) & 9 & 0 & 9 & 4 & 0 & 4 & 1,3 & 1,3 \\
\hline Oxytrigona sp. & 1 & 0 & 1 & & & & 2 & \\
\hline Paratrigona lineata (Lepeletier,1836) & 29 & 2 & 31 & 16 & 0 & 16 & $1,2,3$ & $1,2,3$ \\
\hline Partamona combinata Pedro \& Camargo, 2003 & & & & 5 & 0 & 5 & & 1 \\
\hline Partamona rustica Pedro \& Camargo, 2003 & 3 & 0 & 3 & & & & 2 & \\
\hline Partamona aff. helleri (Friese, 1900) & 1 & 0 & 1 & & & & 1 & \\
\hline Scaptotrigona depilis (Moure,1942) & 364 & 0 & 364 & 116 & 0 & 116 & $1,2,3$ & $1,2,3$ \\
\hline Scaptotrigona polysticta Moure, 1950 & 11 & 0 & 11 & 42 & 0 & 42 & 1,2 & 1,2 \\
\hline Schwarziana mourei Melo, 2003 & 1 & 0 & 1 & 1 & 0 & 1 & 1 & 3 \\
\hline Tetragonisca angustula (Latreille, 1811) & 43 & 0 & 43 & 11 & 0 & 11 & $1,2,3$ & $1,2,3$ \\
\hline Trigona hyalinata (Lepeletier, 1836) & 2 & 1 & 3 & 1 & 0 & 1 & $1,2,3$ & 2 \\
\hline Trigona spinipes (Fabricius, 1793) & 19 & 2 & 21 & 4 & 0 & 4 & $1,2,3$ & 1,3 \\
\hline Apidae / Apinae / Centridini & & & & & & & & \\
\hline Epicharis (Epicharana) flava Friese, 1900 & 0 & 1 & 1 & & & & 3 & \\
\hline Apidae / Apinae / Emphorini & & & & & & & & \\
\hline Alepidosceles imitatrix (Schrottky, 1909) & 0 & 1 & 1 & & & & 1 & \\
\hline Apidae / Apinae /Ericrocidini & & & & & & & & \\
\hline Mesonychium sp. 1 & & & & & & & & \\
\hline Apidae / Apinae / Exomalopsini & & & & & & & & \\
\hline Exomalopsis (Exomalopsis) analis Spinola, 1853 & 21 & 0 & 21 & & & & 2,3 & \\
\hline Exomalopsis (Exomalopsis) ypirangensis Schrottky, 1910 & 2 & 0 & 2 & & & & 1,3 & \\
\hline Exomalopsis (Exomalopsis) minor Schrottky, 1910 & 6 & 1 & 7 & 2 & 0 & 2 & 1,3 & 1 \\
\hline Exomalopsis (Exomalopsis) auropilosa Spinola, 1853 & 1 & 0 & 1 & 2 & 1 & 3 & 3 & 2,3 \\
\hline Exomalopsis (Exomalopsis) cf. tomentosa Friese, 1899 & & & & 1 & 1 & 2 & & 1,2 \\
\hline Exomalopsis (Exomalopsis) fulvofasciata Smith, 1879 & 6 & 0 & 6 & 2 & 0 & 2 & 1,2 & 2 \\
\hline Apidae / Apinae / Tapinotaspidini & & & & & & & & \\
\hline Paratetrapedia (Paratetrapedia) conexa (Vachal, 1909) & 2 & 1 & 3 & & & & 1,2 & \\
\hline Paratetrapedia (Paratetrapedia) sp. & 0 & 1 & 1 & & & & 3 & \\
\hline Paratetrapedia (Tropidopedia) sp. & 0 & 1 & 1 & & & & 3 & \\
\hline Tropidopedia sp. 1 & & & & 0 & 5 & 5 & & 1,3 \\
\hline Xanthopedia sp. 1 & 0 & 3 & 3 & & & & 1,3 & \\
\hline Apidae / Apinae / Tetrapediini & & & & & & & & \\
\hline
\end{tabular}


Continuação da Tabela 1. Continuation of Table I.

\begin{tabular}{|c|c|c|c|c|c|c|c|c|}
\hline Tetrapedia sp. 1 & 8 & 8 & 16 & & & & $1,2,3$ & \\
\hline Tetrapedia sp. 2 & 2 & 9 & 11 & & & & 3 & \\
\hline \multicolumn{9}{|l|}{ Apidae /Xylocopinae / Ceratinini } \\
\hline Ceratina (Ceratinula) sp. 1 & 0 & 1 & 1 & & & & 2 & \\
\hline Ceratina (Ceratinula) sp. 2 & 3 & 0 & 3 & 1 & 0 & 1 & 1 & 2 \\
\hline Ceratina (Ceratinula) sp. 3 & 9 & 3 & 12 & 7 & 1 & 8 & $1,2,3$ & $1,2,3$ \\
\hline Ceratina (Ceratinula) sp. 4 & 1 & 0 & 1 & & & & 1 & \\
\hline Ceratina (Ceratinula) sp. 5 & & & & 2 & 0 & 2 & & 2 \\
\hline Ceratina (Crewella) sp. & & & & 3 & 0 & 3 & & 1,2 \\
\hline Ceratina (Crewella) sp. 1 & 1 & 0 & 1 & & & & 1 & \\
\hline Ceratina (Crewella) sp. 2 & 0 & 1 & 1 & & & & 2 & \\
\hline Ceratina (Crewella) sp. 3 & 1 & 0 & 1 & & & & 1 & \\
\hline \multicolumn{9}{|l|}{ Apidae / Xylocopinae / Xylocopini } \\
\hline Xylocopa suspecta Moure \& Camargo, 1988 & & & & 1 & 0 & 1 & & 2 \\
\hline \multicolumn{9}{|l|}{ Colletidae/Colletinae } \\
\hline Colletes extensicornis Vachal, 1909 & & & & 1 & 1 & 2 & & 1 \\
\hline Colletes petropolitanus Dalla Torre, 1896 & 3 & 1 & 4 & 1 & 2 & 3 & $1,2,3$ & 1 \\
\hline \multicolumn{9}{|l|}{ Colletidae/Hylaeinae } \\
\hline Hylaeus (Hylaeopsis) sp. 1 & 2 & 0 & 2 & 1 & 0 & 1 & 2,3 & 1 \\
\hline Hylaeus (Hylaeopsis) sp. 2 & 1 & 0 & 1 & 1 & 0 & 1 & 3 & 1 \\
\hline Hylaeus (Hylaeopsis) sp. 3 & 0 & 1 & 1 & & & & 3 & \\
\hline Hylaeus (Hylaeana) sp. 4 & 4 & 0 & 4 & 1 & 0 & 1 & $1,2,3$ & 1 \\
\hline Hylaeus (Cephylaeus) sp. 5 & 0 & 13 & 13 & 6 & 0 & 6 & $1,2,3$ & 2,3 \\
\hline Hylaeus (Hylaeopsis) sp. 6 & 0 & 1 & 1 & & & & 2 & \\
\hline Hylaeus (Hyaleana) sp. 7 & 3 & 0 & 3 & 3 & 0 & 3 & $1,2,3$ & 2,3 \\
\hline Hylaeus (Hyaleana) sp. 8 & 1 & 0 & 1 & & & & 3 & \\
\hline Hylaeus (Hyaleana) sp. 9 & 4 & 0 & 4 & 2 & 0 & 2 & 1,3 & 1 \\
\hline Hylaeus sp. 11 & & & & 1 & 0 & 1 & & 1 \\
\hline Hylaeus sp. 12 & & & & 2 & 0 & 2 & & 1 \\
\hline \multicolumn{9}{|l|}{ Halictidae/Halictinae / Augochlorini } \\
\hline Augochlora sp. 1 & 3 & 0 & 3 & & & & 1,2 & \\
\hline Augochlora sp. 2 & 2 & 0 & 2 & 1 & 0 & 1 & 1,2 & 2 \\
\hline Augochlora sp. 3 & 2 & 0 & 2 & 1 & 0 & 1 & 1,2 & 2 \\
\hline Augochlora sp. 4 & 1 & 0 & 1 & & & & 1 & \\
\hline Augochlora sp. 5 & 0 & 1 & 0 & & & & 3 & \\
\hline Augochlora sp. 6 & & & & 1 & 0 & 1 & & 3 \\
\hline Augochloropsis sp. & & & & 1 & 0 & 1 & & 1 \\
\hline Augochloropsis sp. 1 & 2 & 0 & 2 & & & & 1,2 & \\
\hline Augochloropsis sp. 2 & 0 & 1 & 1 & 1 & 0 & 1 & 2 & 3 \\
\hline Augochloropsis sp. 3 & & & & 0 & 1 & 1 & & 3 \\
\hline Augochloropsis smithiana (Cockerell,1900) & 7 & 2 & 9 & 5 & 0 & 5 & $1,2,3$ & 2,3 \\
\hline Augochloropsis aurifluens (Vachal, 1903) & 12 & 4 & 16 & 4 & 0 & 4 & $1,2,3$ & 1,3 \\
\hline Augochloropsis brachycephala Moure, 1943 & 2 & 1 & 3 & 3 & 0 & 3 & $1,2,3$ & 1,3 \\
\hline Augochloropsis callichroa (Cockerell, 1900) & 24 & 8 & 32 & 9 & 5 & 14 & $1,2,3$ & 2,3 \\
\hline Augochloropsis patens (Vachal, 1903) & 2 & 0 & 2 & 0 & 1 & 1 & 1 & 1 \\
\hline Augochloropsis cfr. wallacei (Cockerell, 1900) & 1 & 1 & 2 & & & & 3 & \\
\hline Ceratalictus sp. & 10 & 0 & 10 & 2 & 0 & 2 & $1,2,3$ & 1,2 \\
\hline Paraxystoglossa mimetica Moure, 1950 & 2 & 2 & 4 & & & & $1,2,3$ & \\
\hline Temnosoma sp. & 4 & 4 & 8 & & & & $1,2,3$ & \\
\hline Temnosoma sp. 1 & & & & 3 & 2 & 5 & & 1,3 \\
\hline Temnosoma cf. metallicum (Smith, 1853) & & & & 1 & 2 & 3 & & 2 \\
\hline Thectochlora sp. & 3 & 0 & 3 & & & & 1,3 & \\
\hline
\end{tabular}


Continuação da Tabela 1. Continuation of Table I.

\begin{tabular}{|c|c|c|c|c|c|c|c|c|}
\hline Thectochlora alaris (Vachal, 1904) & & & & 4 & 0 & 4 & & 1,3 \\
\hline Thectochlora brachycera Gonçalves \& Melo, 2006 & & & & 1 & 0 & 1 & & 2 \\
\hline Rhinocorynura crotonis (Ducke, 1906) & & & & 3 & 0 & 3 & & 2,3 \\
\hline \multicolumn{9}{|l|}{ Halictidae/Halictinae / Halictini } \\
\hline Caenohalictus sp. & 1 & 1 & 2 & 3 & 0 & 3 & 3 & 3 \\
\hline Dialictus sp. & & & & 1 & 0 & 1 & & 1 \\
\hline Dialictus sp. 1 & 1 & 0 & 1 & & & & 1 & \\
\hline Dialictus sp. 2 & 1 & 0 & 1 & & & & 2 & \\
\hline Dialictus sp. 3 & & & & 0 & 1 & 1 & & 2 \\
\hline Dialictus sp. 4 & & & & 1 & 0 & 1 & & 1 \\
\hline Dialictus sp. 5 & & & & 1 & 0 & 1 & & 3 \\
\hline \multicolumn{9}{|l|}{ Megachilidae/Megachilinae / Anthidiini } \\
\hline Anthodioctes megachiloides Holmberg, 1903 & 1 & 0 & 1 & & & & 2 & \\
\hline Dicranthidium sp. 1 & 4 & 0 & 4 & & & & 3 & \\
\hline \multicolumn{9}{|l|}{ Megachilidae/Megachilinae /Megachilini } \\
\hline Coelioxys sp. 1 & 0 & 1 & 1 & & & & 3 & \\
\hline Coelioxys sp. 2 & 0 & 1 & 1 & & & & 3 & \\
\hline Megachile (Moureapis) sp. 1 & 1 & 0 & 1 & 0 & 2 & 2 & 3 & 3 \\
\hline Megachile (Ptilosarus) sp. 1 & 1 & 0 & 1 & & & & 2 & \\
\hline Megachile (Austrosaurus) frankiena Raw, 2006 & & & & 1 & 0 & 1 & & 2 \\
\hline Megachile (Neochelynea) paulista (Schrottky, 1920) & 0 & 1 & 1 & & & & 3 & \\
\hline Megachile (Trichurochile) gracilis Schrottky,1902 & 3 & 1 & 4 & 0 & 3 & 3 & 1,3 & 3 \\
\hline Megachile (Pseudocentron) curvipes Smith, 1853 & 1 & 0 & 1 & 1 & 0 & 1 & 2 & 3 \\
\hline Megachile (Pseudocentron) terrestris & & & & 0 & 1 & 1 & & 2 \\
\hline Total de espécies na $1^{\mathrm{a}}$ etapa & 1428 & 89 & 1516 & & & & & \\
\hline Total de espécies na $2^{\mathrm{a}}$ etapa & & & & 532 & 30 & 562 & & \\
\hline Total geral de espécies/indivíduos & & & & & & & & \\
\hline
\end{tabular}

Tabela 2. Número de espécies e de indivíduos de abelhas da família Apidae, visitantes de Matayba guianensis em cerrados de Uberlândia, MG, no período de outubro a dezembro/2005 ( $1^{\mathrm{a}}$ etapa) e outubro a dezembro/2006 ( $2^{\mathrm{a}}$ etapa).

Table2. Number of species and individuals from bee family Apidae that visit Matayba guianensis in cerrado at Uberlandia, Minas Gerais, from October to December/2005 (first stage) and from October to December/2006 (second stage).

\begin{tabular}{|c|c|c|c|c|c|c|}
\hline \multirow[b]{2}{*}{ Subfamilia } & \multirow[b]{2}{*}{ Tribo } & \multirow[b]{2}{*}{ Subtribo } & \multicolumn{2}{|c|}{$1^{\mathrm{a}}$ etapa } & \multicolumn{2}{|c|}{$2^{a}$ etapa } \\
\hline & & & $\begin{array}{c}\mathrm{N}^{0} \text { de } \\
\text { espécies }\end{array}$ & $\begin{array}{c}\mathrm{N}^{\mathbf{0}} \text { de } \\
\text { indivíduos }\end{array}$ & $\begin{array}{c}N^{0} \text { de } \\
\text { espécies }\end{array}$ & $\begin{array}{c}\mathrm{N}^{0} \mathrm{de} \\
\text { indivíduos }\end{array}$ \\
\hline \multirow[t]{10}{*}{ Apinae } & Apini & Apina & 1 & 635 & 1 & 183 \\
\hline & & Bombina & 1 & 7 & - & - \\
\hline & & Euglossina & 1 & 1 & - & - \\
\hline & & Meliponina & 17 & 512 & 14 & 216 \\
\hline & Centridini & - & 1 & 1 & - & - \\
\hline & Emphorini & - & 1 & 1 & - & - \\
\hline & Ericrocidini & - & - & - & 1 & 1 \\
\hline & Exomalopsini & - & 5 & 37 & 4 & 9 \\
\hline & Tapinotaspidini & - & 4 & 8 & 1 & 5 \\
\hline & Tetrapediini & - & 2 & 27 & 2 & 3 \\
\hline \multirow[t]{2}{*}{ Xylocopinae } & Ceratinini & - & 7 & 20 & 4 & 14 \\
\hline & Xylocopini & - & - & - & 1 & 1 \\
\hline Total & & & 40 & 1249 & 28 & 432 \\
\hline
\end{tabular}


Tabela 3. Número de espécies e de indivíduos de abelhas das famílias Andrenidae, Colletidae, Halictidae e Megachilidae, visitantes de Matayba guianensis, coletados em cerrados de Uberlândia, MG. Outubro a dezembro/2005 ( $1^{\mathrm{a}}$ etapa) e outubro a dezembro/2006 ( $2^{\mathrm{a}}$ etapa).

Table 3. Number of species and individuals from families Andrenidae, Colletidae, Halictidae e Megachilidae that visit Matayba guianensis, sampled in cerrado at Uberlândia, MG. October to December/2005 (first stage) and October to December/2006 (second stage).

\begin{tabular}{|c|c|c|c|c|c|c|}
\hline Família & Subfamilia & Tribo & \multicolumn{2}{|c|}{$1^{\mathrm{a}}$ etapa } & \multicolumn{2}{|c|}{$2^{\mathrm{a}}$ etapa } \\
\hline Andrenidae & Panurginae & Protandrenini & 1 & 114 & 1 & 42 \\
\hline Colletidae & Colletinae & - & 1 & 4 & 2 & 5 \\
\hline Halictidae & & Halictini & 3 & 4 & 5 & 7 \\
\hline \multirow[t]{2}{*}{ Megachilidae } & Megachilinae & Anthidiini & 2 & 5 & - & - \\
\hline & & Megachilini & 7 & 10 & 5 & 8 \\
\hline Total & & & 40 & 267 & 38 & 130 \\
\hline
\end{tabular}

espécies: A. mellifera, com $635(41,88 \%)$ e 183 (32,6\%) indivíduos, respectivamente, na primeira e segunda etapas e Scaptotrigona depilis, com 364 (24\%) abelhas na primeira etapa e $116(20,6 \%)$ na segunda (Tabela 1).

Andrenidae foi a segunda família em número de indivíduos, na primeira etapa, com 114 abelhas $(7,52 \%$ do total), todas da espécie Rophitulus sp., seguida por Halictidae, com 105 indivíduos (6,86\%), Colletidae, com 34 indivíduos $(2,24 \%)$ e por Megachilidae, com apenas 15 abelhas $(0,98 \%)$ - Tabela 3 .

$\mathrm{Na}$ segunda etapa, após Apidae aparece a família Halictidae, com 58 indivíduos (10,3\%), seguida por Andrenidae com 42 (7,5\%), Colletidae com 22 abelhas (3,9\%) e por Megachilidae, com apenas oito exemplares $(1,4 \%)$ - Tabela 3 .

A seqüência das famílias em número de indivíduos, na primeira etapa, foi: Apidae > Andrenidae > Halictidae $>$ Colletidae $>$ Megachilidae, enquanto que na segunda etapa foi: Apidae > Halictidae $>$ Andrenidae $>$ Colletidae $>$ Megachilidae, evidenciando uma inversão entre Andrenidae e Halictidae, em comparação com a primeira etapa.

$\mathrm{Na}$ família Apidae, sobressaíram os gêneros Exomalopsis com seis espécies e Ceratina com nove (Tabela 1). Meliponina foi a subtribo de Apidae melhor representada na amostra, com 17 (42,5\%) espécies e 512 indivíduos na primeira etapa e 14 (50\%) espécies e 216 indivíduos na segunda (Tabela 2). Na família Halictidae, a tribo mais representada foi Augochlorini, com 17 das 20 espécies (85\%) na primeira etapa e 17 das $22(77,3 \%)$ na segunda etapa (Tabela 3). Ao nível de gênero, sobressaíram Augochlora, com seis espécies e Augochloropsis, com dez (Tabela 1). Em Colletidae, a grande maioria das abelhas coletadas pertence ao gênero Hylaeus, com 11 espécies. Já na família Megachilidae apareceram quatro gêneros, destacando-se Megachile com sete espécies. Apenas o gênero Rophitulus foi encontrado na família Andrenidae, com uma espécie (Tabela 1).

Das espécies coletadas, $46,25 \%(\mathrm{~N}=80)$ na primeira etapa e $56,1 \%(\mathrm{~N}=66)$ na segunda foram representadas apenas por um ou dois indivíduos, ou seja, são espécies raras. Poucas espécies foram representadas por um grande número de indivíduos, como A. mellifera, S. depilis, Rophitulus sp., Tetragonisca angustula e Scaptotrigona polysticta.

Foram amostrados 89 machos $(5,9 \%)$ na primeira etapa e $30(5,3 \%)$ na segunda, sendo que nas espécies sociais, como A. mellifera, S. depilis, Nannotrigona testaceicornis, Paratrigona lineata e T. angustula, eles foram pouco ou nada coletados. Apareceram com maior freqüência em alguns gêneros de abelhas solitárias, como Tetrapedia, Hylaeus, Tropidopedia e Augochloropsis (Tabela 1).

Quanto ao local de ocorrência, as espécies mais abundantes geralmente foram coletadas nas três áreas de estudo, com exceção de $S$. polysticta, não coletada na SC nas duas etapas e de Rophitulus sp., também não coletada nessa área na segunda etapa. Espécies raras geralmente ocorreram apenas em uma área,como Schwarziana mourei e Partamona aff. helleri (EEP), Anthodioctes megachiloides (FPB) e Augochloropsis cfr. wallacei (SC). No entanto, há casos de espécies raras representadas por apenas três ou quatro indivíduos, como Hylaeus (Hylaena) sp. 4 e Trigona hyalinata, encontradas nas três áreas. Espécies de Melipona só foram coletadas na EEP 
e na FPB. Das espécies de Megachilidae, apenas Megachile (Trichurochile) gracilis foi coletada na EEP (Tabela 1).

\section{PADRÃO DE VISITAÇÃO DAS ABELHAS NA PRIMEIRA ETAPA}

Número de indivíduos e de espécies coletadas

De maneira geral, coletaram-se mais abelhas no período da manhã, entre $8 \mathrm{~h}$ e $12 \mathrm{~h}$. Na SC, o número de abelhas coletado a partir das $10 \mathrm{~h}$ foi maior do que nas outras duas áreas (Figura 3 ).

$\mathrm{O}$ número total de indivíduos de abelhas, em cada área, seguiu o padrão da curva do número de indivíduos de $A$. mellifera, a espécie mais abundante (Figura 4). O número de $A$. mellifera em relação ao número total de abelhas coletadas foi maior na $\mathrm{SC}$, onde a curva que representa o número de $A$. mellifera está mais próxima da curva do número total de indivíduos de todas as espécies.

Na EEP, coletou-se um total de 521 abelhas, sendo 151 (28,9\%) A. mellifera. A maior concentração ocorreu nas coletas 4 e 5 em dezembro, quando foram capturadas 59,9\% das abelhas dessa área (Figura 4).

Na FPB foram coletadas 419 abelhas e destas, 126 (30,1\%) eram A. mellifera, ou seja, uma porcentagem bem próxima da encontrada na EEP. Do total de abelhas deste local, a maioria, $383(69,2 \%)$ foi capturada nas coletas 3 e 4, em dezembro. Também

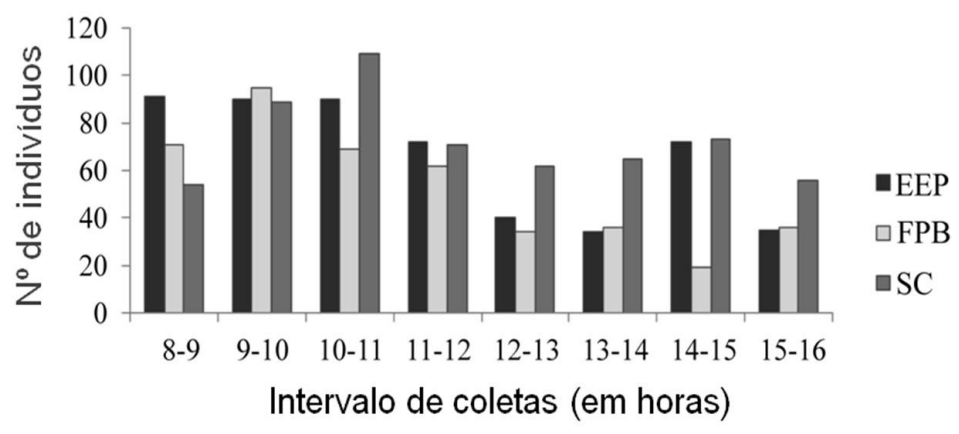

Figura 3. Número de abelhas coletadas em Matayba guianensis em áreas de cerrado em Uberlândia, MG, de acordo com o horário de coleta. Outubro a dezembro/2005 (EEP: Estação Ecológica do Panga; FPB: cerrado na Fazenda Palma da Babilônia; SC: reserva na Souza Cruz).

Figure 3. Number of bees sampled on Matayba guianensis in cerrado areas at Uberlandia, Minas Gerais, in relation to the sample timetable. October to December/2005 (EEP: Panga Ecological Reserve; FPB: cerrado at Fazenda Palma da Babilonia; SC: Souza Cruz Reserve).
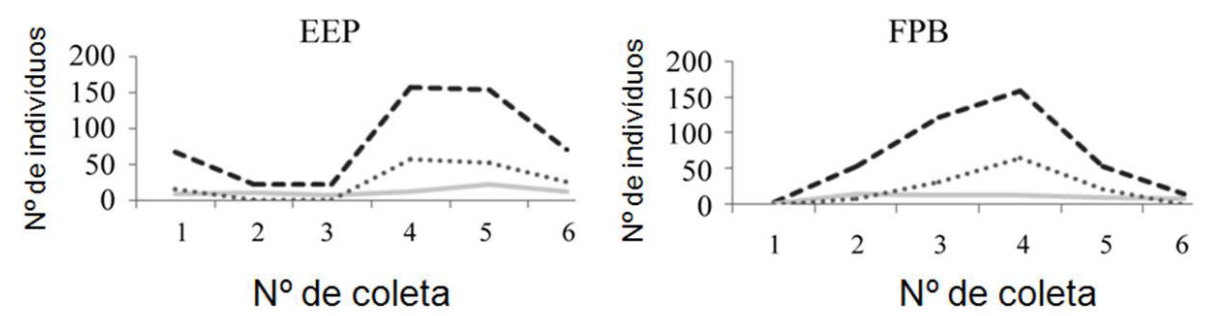

SC
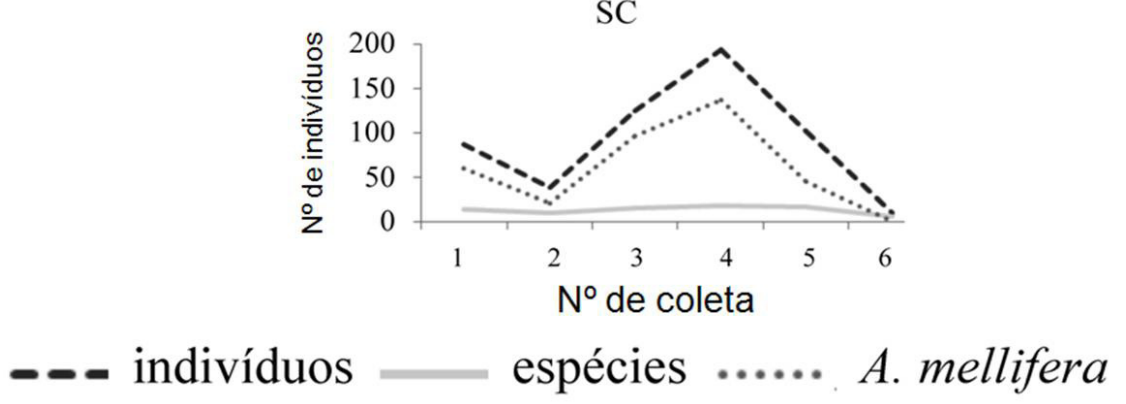

Figura 4. Número de indivíduos, de espécies e de abelhas de Apis mellifera coletados em Matayba guianensis em cerrados de Uberlândia, MG. Outubro a dezembro/2005 (EEP: Estação Ecológica do Panga, FPB: cerrado na Fazenda Palma da Babilônia, SC: reserva Souza Cruz.

Figure 4. Number of individuals, species and Apis mellifera bees sampled on Matayba guianensis in cerrado at Uberlandia, Minas Gerais. October to December/2005 (EEP: Panga Ecological Reserve; FPB: cerrado at Fazenda Palma da Babilonia; SC: Souza Cruz Reserve). 
na coleta 4 ocorreu o pico de A. mellifera (Figura 4), que representou $40,62 \%$ das abelhas coletadas neste dia.

Nas seis coletas realizadas na SC, foram capturadas 576 abelhas, sendo 358 A. mellifera, ou seja, $62,15 \%$, um número elevado quando comparado com as outras duas áreas. Na coleta 6 não foi capturada nenhuma abelha A. mellifera (Figura 4). Nessa coleta, só foram encontrados dois indivíduos pouco atrativos de $M$. guianensis, com flores mais velhas. Todos os indivíduos restantes estavam com frutos em diferentes estágios ou eram indivíduos com flores estaminadas. As abelhas $A$. mellifera, em coletas anteriores, foram mais freqüentemente encontradas em plantas com muitas flores e que estavam sendo também visitadas por várias vespas e muitas abelhas, principalmente da espécie $S$. depilis. Ou seja, visitavam plantas atrativas, ricas em recurso floral.

$\mathrm{Na} \mathrm{SC}$, a exemplo da FPB, o pico de captura se deu nas coletas 3 e 4 (Figura 4) no final de novembro e início de dezembro, quando foram .capturadas 317 abelhas (55,03\% do total de abelhas desta área).

Horário de visita das quatro espécies mais comuns

As quatro espécies de abelhas mais abundantes na primeira etapa foram $A$. mellifera, $S$. depilis Rophitulus sp. e T. angustula. Considerando-se as três áreas no geral, A. mellifera e $S$. depilis foram coletadas ao longo de todo o intervalo de coleta. A. mellifera foi mais abundante na $\mathrm{SC}$ e $S$. depilis foi mais abundante na EEP e na FPB. T. angustula e Rophitulus sp. foram mais comuns no período da manhã, de $8 \mathrm{~h}$ às $12 \mathrm{~h}$. Rophitulus sp. foi mais comum na FPB, aparecendo com poucos indivíduos na SC. $T$. angustula foi coletada em todos os horários na EEP, mas não nas outras duas áreas (Figura 5).

Considerando-se as três áreas separadamente, na EEP A. mellifera foi representada por 151 abelhas, $S$. depilis por 192, Rophitulus sp. por 46 e T. angustula, por 28 abelhas. A. mellifera foi coletada em pequeno número no horário de $8 \mathrm{~h}$ às $9 \mathrm{~h}$, quando ocorreu o pico de S. depilis (Figura 5). A correlação de Pearson mostrou que não houve relação significativa entre a abundância da distribuição de $A$. mellifera e S.depilis $(\mathrm{r}=0,410 ; \mathrm{p}=0,314)$

Na FPB, A. mellifera, S. depilis, Rophitulus sp. e T. angustula foram representadas, respectivamente, por 126, 111, 64 e cinco indivíduos. Verifica-se que não houve grandes diferenças no padrão de visitas das duas espécies mais abundantes, tendo sido ambas mais frequentes no período da manhã. Sobressai nessa área o pico de Rophitulus sp., no horário de $11 \mathrm{~h}$ às $12 \mathrm{~h}$, quando diminuiu a coleta de A. mellifera e S.depilis (Figura 5). A correlação de Pearson foi significativa para essas duas últimas espécies $(\mathrm{r}=0,832 ; \mathrm{p}=0,010)$,
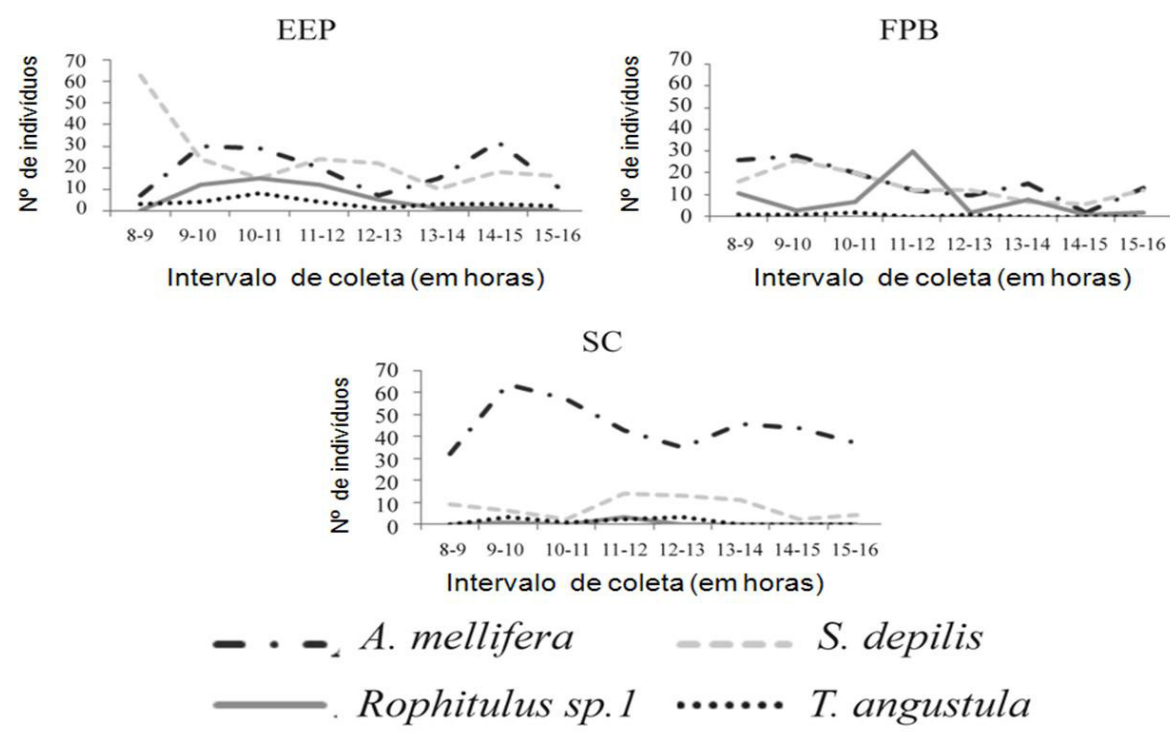

Figura 5. Horário de atividade das abelhas mais comuns em flores de Matayba guianensis em áreas de cerrado de Uberlândia, MG. Outubro a dezembro/2005. (EEP: Estação Ecológica do Panga; FPB: cerrado na Fazenda Palma da Babilônia; SC: reserva na Souza Cruz).

Figure 5. Activity timetable of the most common bees on Matayba guianensis flowers in cerrado areas at Uberlândia, Minas Gerais. October to December/2005 (EEP: Panga Ecological Reserve; FPB: cerrado at Fazenda Palma da Babilonia; SC: Souza Cruz Reserve). 
mostrando uma relação positiva entre elas: quando o número de indivíduos de uma espécie aumenta, o da outra também aumenta.

Quanto à $\mathrm{SC}$, as quatro espécies de abelhas $A$. mellifera, S. depilis, Rophitulus sp. e T. angustula estiveram representadas por 358,61 , quatro e 10 indivíduos, respectivamente. A. mellifera foi coletada em maior número que $S$. depilis, na $\mathrm{SC}$, em todos os horários. O pico de $A$. mellifera ocorreu de $9 \mathrm{~h}$ ás $10 \mathrm{~h}$, quando foram coletadas poucas $S$. depilis (Figura 5). A correlação de Pearson não indicou relação significativa entre as abundâncias de $A$. mellifera e $S$. depilis $(\mathrm{r}=-0,392 ; \mathrm{p}=0,337)$.

\section{PADRÃO DE VISITAÇÃO DAS ABELHAS NA SEGUNDA ETAPA}

\section{Número de indivíduos e de espécies coletadas}

Nas três áreas amostradas, a coleta foi mais intensa até às $12 \mathrm{~h}$, diminuindo no horário de $12 \mathrm{~h}$ às $13 \mathrm{~h}$. Na EEP e na FPB, a coleta foi maior entre $10 \mathrm{~h}$ e $11 \mathrm{~h}$ e na $\mathrm{SC}$, entre $11 \mathrm{~h}$ e $12 \mathrm{~h}$ (Figura 6 ).

O padrão diário para o número total de indivíduos coletados em cada área é semelhante à curva do número de indivíduos de $A$. mellifera em cada área. A coleta mais representativa em número de indivíduos foi a coleta 2. Em número de espécies também foi a coleta 2, exceto na EEP, onde a coleta 3 foi a mais rica (Figura 7).

Destacando-se cada área em separado, na EEP foram capturadas 208 abelhas nas cinco coletas. O número de abelhas variou de 25 , na coleta 5 , a 54 , na coleta 2 . A riqueza variou de 11 a 16 espécies. $\mathrm{O}$ número de $A$. mellifera coletadas esteve entre zero, na coleta 5, e 26, na coleta 2. Do total capturado na EEP, 70 (33,6 \%) eram A. mellifera.

Na FPB coletaram-se 166 abelhas, de 20 a 58 indivíduos por coleta. A riqueza de espécies ficou entre 7 a 16 espécies por coleta. O número de $A$. mellifera foi pequeno, 28 abelhas no total $(16,9 \%)$. A espécie esteve ausente nas duas últimas coletas na FPB (Figura 7).

$\mathrm{Na}$ SC foram capturadas 188 abelhas. A coleta 5 foi pouco representativa, com 19 exemplares e a mais representativa foi a coleta 2 , com 59 abelhas e 14 espécies. O número de espécies variou de seis a 14 (Figura 7). A espécie A. mellifera foi capturada em todas as coletas, totalizando 85 abelhas na SC $(45,2 \%)$. Como na primeira etapa, a porcentagem de A mellifera foi maior na $\mathrm{SC}$ do que nas outras duas áreas.

Horário de visitas das quatro espécies mais comuns

Os horários em que foram coletadas as quatro espécies de abelhas mais comuns na segunda etapa, A. mellifera, S. depilis, S. polysticta e Rophitulus sp., encontram-se na Figura 8. A. mellifera e $S$. depilis foram capturadas nas três áreas durante todo o período de coleta. Rophitulus sp. e S. polysticta não foram coletadas na SC. Nas outras duas áreas, foram capturadas principalmente até às $11 \mathrm{~h}$.

Na EEP, A. mellifera atingiu o pico no horário de $10 \mathrm{~h}$ às $11 \mathrm{~h}$ e Scaptotrigona depilis, de $11 \mathrm{~h}$ às $12 \mathrm{~h}$, quando A. mellifera diminuiu. Na FPB, o pico de tres espécies ocorreu de 10 as $11 \mathrm{~h}$ e de Rophitulus sp., de $9 \mathrm{~h}$ às $10 \mathrm{~h}$. Na SC, quando o número de indivíduos de

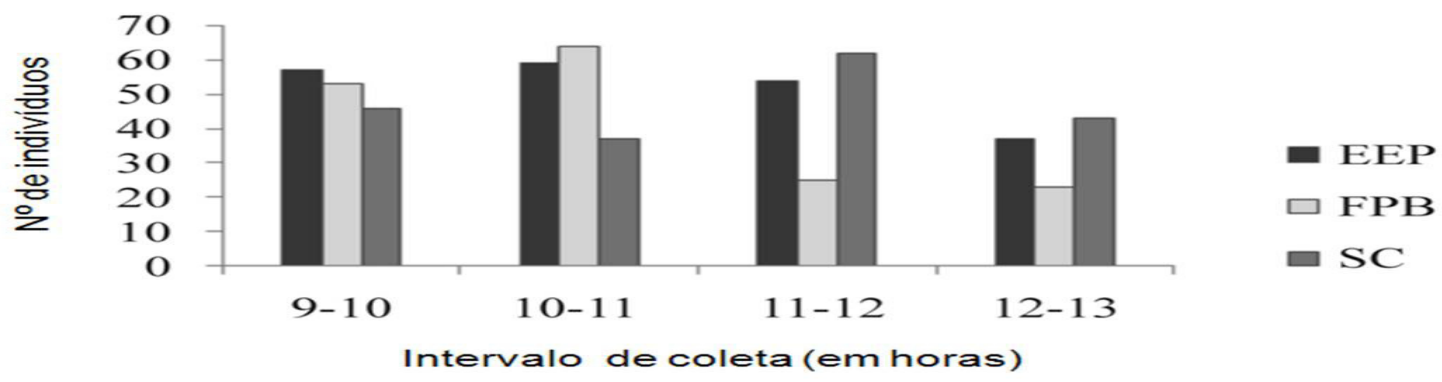

Figura 6. Número de abelhas coletadas em Matayba guianensis em áreas de cerrado em Uberlândia, MG, de acordo com o horário de coleta. Outubro a dezembro/2006 (EEP: Estação Ecológica do Panga; FPB: cerrado na Fazenda Palma da Babilônia; SC: reserva na Souza Cruz).

Figure 6. Number of bees sampled on Matayba guianensis in cerrado areas at Uberlândia, Minas Gerais, in relation to the sample timetable. October to December/2006 (EEP: Panga Ecological Reserve; FPB: cerrado at Fazenda Palma da Babilonia; SC: Souza Cruz Reserve). 

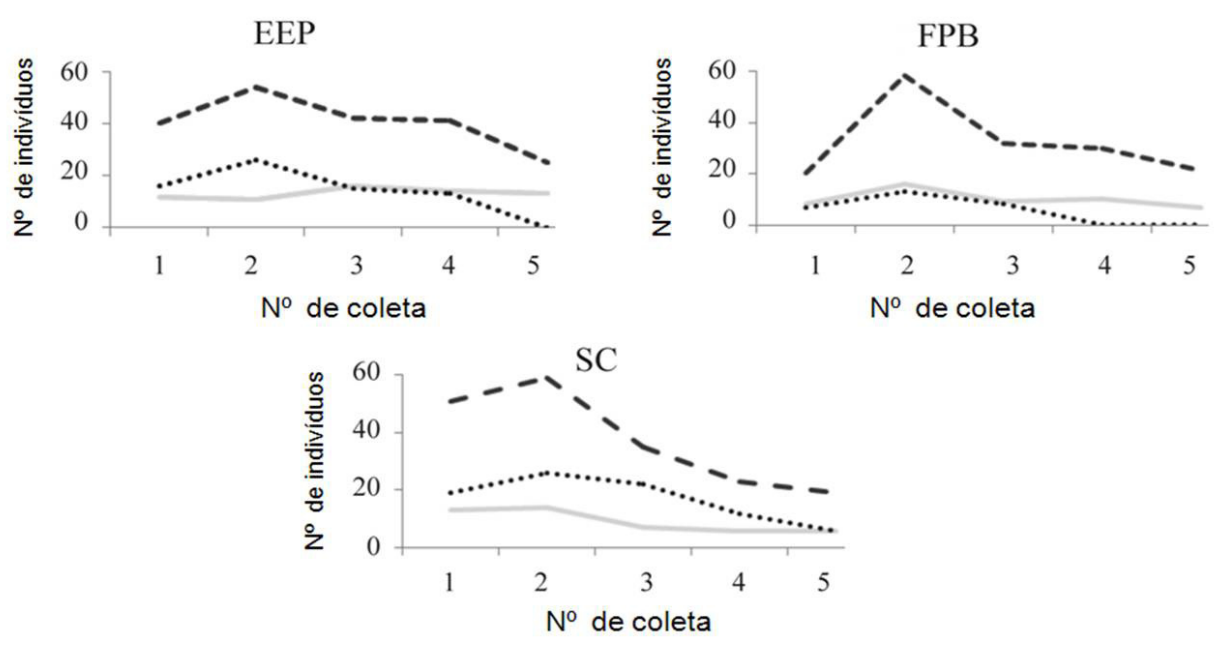

\section{- - indivíduos $=$ espécies ....... A. mellifera}

Figura 7. Número de espécies, de indivíduos e de abelhas Apis mellifera coletados em Matayba guianensis em áreas de cerrado em Uberlândia, MG. Outubro a dezembro/2006 (EEP: Estação Ecológica do Panga; FPB: cerrado na Fazenda Palma da Babilônia; SC: reserva da Souza Cruz).

Figure 7. Number of individuals, species and Apis mellifera bees sampled on Matayba guianensis in cerrado at Uberlândia, Minas Gerais. October to December/2006 (EEP: Panga Ecological Reserve; FPB: cerrado at Fazenda Palma da Babilônia; SC: Souza Cruz Reserve).
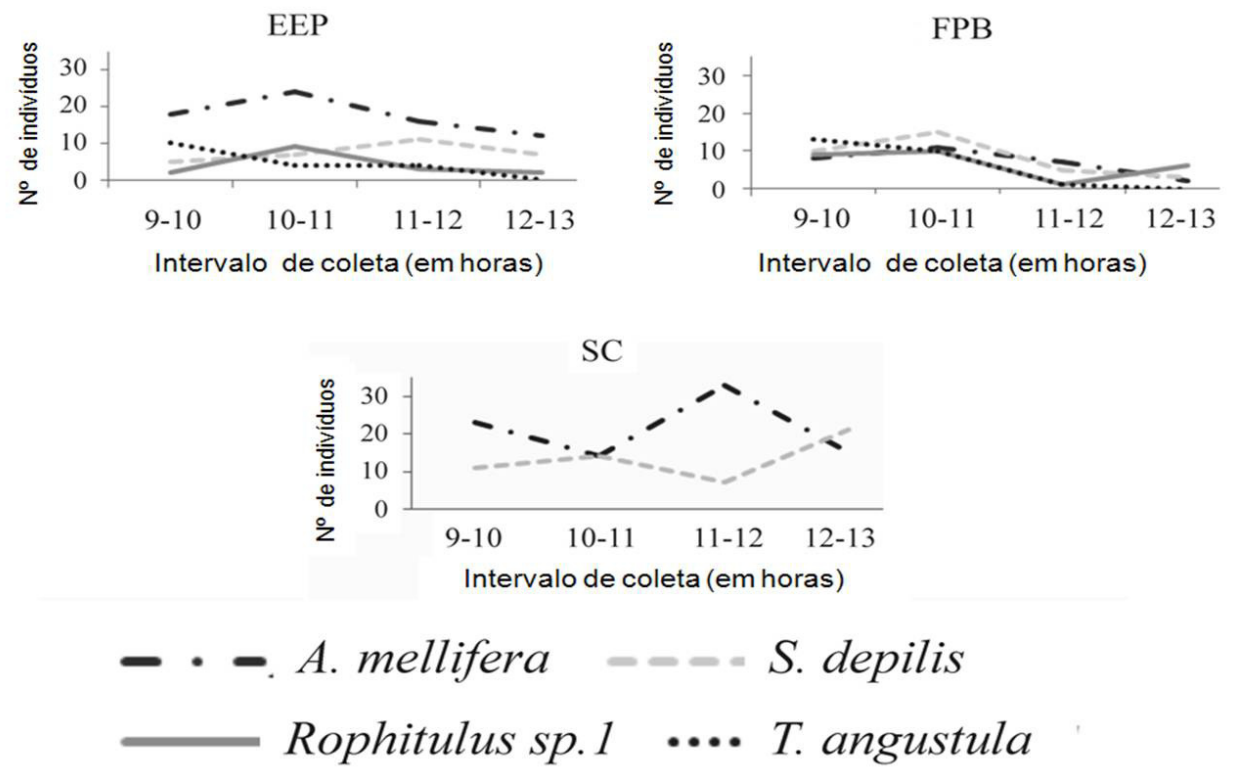

Figura 8. Horário de atividade das abelhas mais comuns em flores de Matayba guianensis em cerrados de Uberlândia, MG. Outubro a dezembro/2006 (EEP: Estação Ecológica do Panga; FPB: cerrado na Fazenda Palma da Babilônia; SC: reserva na Souza Cruz).

Figure 8. Activity timetable of the most common bees on Matayba guianensis flowers in cerrado areas at Uberlândia, Minas Gerais. October to December/2006 (EEP: Panga Ecological Reserve; FPB: cerrado at Fazenda Palma da Babilonia; SC: Souza Cruz Reserve).

A. mellifera diminuía em um horário, o de $S$. depilis aumentava (Figura 8). A SC foi a área onde foram capturados mais exemplares de A. mellifera (85) e de S. depilis (53) na segunda etapa.

A correlação de Pearson entre a abundância de $A$. mellifera e $S$. depilis na segunda etapa, nos quatro períodos ao longo do dia, não foi significativa em nenhuma área ( $(\mathrm{r}=-0,185 ; \mathrm{p}=0,815)$ na EEP; $(\mathrm{r}=$ $0,911 ; p=0,089)$ na FPB e $(r=-0,841 ; p=0,159)$ na $\mathrm{SC})$.

\section{ESPÉCIES DE ABELHAS QUE VISITARAM UMA MESMA PLANTA DE Matayba guianensis NO MESMO HORÁRIO}

Nas plantas marcadas foram registradas 43 espécies de abelhas, considerando-se as três áreas. Em 34 (64,1\%) dos 53 intervalos de uma hora, nos quais foram coletadas abelhas, foram observadas três ou mais espécies forrageando na mesma planta e ao mesmo tempo (Tabela 4). 
Foram registradas até seis espécies de abelhas visitando concomitantemente uma mesma planta de $M$. guianensis. As quatro espécies de abelhas mais comuns na segunda etapa $(1,2,3$ e 4), foram registradas em todos os horários de coleta, sendo observadas uma, duas, três ou quatro dessas espécies ao mesmo tempo. Indivíduos de $A$. mellifera e $S$. depilis geralmente estavam forrageando juntos (Tabela 4).

Das espécies coletadas nas plantas marcadas, apenas Cephalotrigona capitata, Temnosoma cfr. metallicum e Tetrapedia sp.2 não foram coletadas forrageando junto com A. mellifera.

Abelhas pequenas, como Paratrigona lineata, Nannotrigona testaceicornis e T. angustula foram capturadas forrageando na mesma planta e no mesmo horário com espécies agressivas ou maiores, como A. mellifera, S. polysticta, Augochloropsis sp.,
Geotrigona mombuca e Augochloropsis callichroa, mas geralmente em pequeno número.

\section{ESPÉCIES DOMINANTES DE ABELHAS}

Foram determinadas 24 espécies dominantes de abelhas na primeira etapa da coleta, representando 30\% das espécies identificadas (Figura 9). Dessas 24 espécies, 17 eram da família Apidae, englobando 1211 do total (97\%) das 1249 abelhas Apidae capturadas. O restante das espécies dominantes ficou assim distribuído: uma na família Colletidae, com 13 dos 34 indivíduos desta família; cinco na família Halictidae, com 75 das 105 abelhas; uma na família Andrenidae, com todos os 114 indivíduos da família. Na família Megachilidae não foi encontrada nenhuma espécie dominante. Os extremos das barras horizontais representam os limites de confiança e a

Tabela 4. Espécies de abelhas visitantes de uma mesma planta de Matayba guianensis, em um mesmo horário, em cerrados do município de Uberlândia, MG. Outubro a dezembro/2006. (EEP: Estação Ecológica do Panga; FPB: cerrado na Fazenda Palma da Babilônia; SC: Reserva da Souza Cruz).

Table 4. Bee species that visit one single Matayba guianensis plant, at the same time, in cerrado at Uberlândia, Minas Gerais. October to December/2006 (EEP: Panga Ecological Reserve; FPB: cerrado at Fazenda Palma da Babilonia; SC: Souza Cruz Reserve).

\begin{tabular}{|c|c|c|c|c|c|}
\hline Planta marcada & Local & Data & Horário & $\mathrm{N}^{\mathrm{o}}$ de abelhas & Espécies \\
\hline 1 & EEP & $24 / 10 / 06$ & $9 \mathrm{~h}-10 \mathrm{~h}$ & 5 & $1,2,5,6,7$ \\
\hline \multirow[t]{2}{*}{2} & EEP & $10 / 10 / 06$ & $9 \mathrm{~h}-10 \mathrm{~h}$ & 3 & 1,9 \\
\hline & & $24 / 10 / 06$ & $10 \mathrm{~h}-11 \mathrm{~h}$ & 10 & $1,2,3,8,10$ \\
\hline 3 & EEP & $10 / 10 / 06$ & $10 \mathrm{~h}-11 \mathrm{~h}$ & 3 & 1,11 \\
\hline 4 & EEP & $24 / 10 / 06$ & $10 \mathrm{~h}-11 \mathrm{~h}$ & 4 & $1,2,3,10$ \\
\hline \multirow[t]{4}{*}{5} & EEP & $10 / 10 / 06$ & $10 \mathrm{~h}-11 \mathrm{~h}$ & 8 & $1,2,12$ \\
\hline & & $24 / 10 / 06$ & $10 \mathrm{~h}-11 \mathrm{~h}$ & 5 & $1,2,3$ \\
\hline & & 07/11/06 & $9 \mathrm{~h}-10 \mathrm{~h}$ & 8 & $1,2,3,4,13$ \\
\hline & & $21 / 11 / 06$ & $10 \mathrm{~h}-11 \mathrm{~h}$ & 5 & $1,3,14$ \\
\hline \multirow[t]{2}{*}{6} & EEP & $10 / 10 / 06$ & $10 \mathrm{~h}-11 \mathrm{~h}$ & 3 & 2,3 \\
\hline & & $07 / 11 / 06$ & $11 \mathrm{~h}-12 \mathrm{~h}$ & 8 & $1,3,12,15,31$ \\
\hline 7 & EEP & $10 / 10 / 06$ & $11 \mathrm{~h}-12 \mathrm{~h}$ & 3 & $1,3,33$ \\
\hline \multirow[t]{2}{*}{8} & EEP & $10 / 10 / 06$ & $12 \mathrm{~h}-13 \mathrm{~h}$ & 6 & $1,3,34,19,33$ \\
\hline & & 07/11/06 & $11 \mathrm{~h}-12 \mathrm{~h}$ & 3 & $1,2,10$ \\
\hline 11 & EEP & 07/11/06 & $9 \mathrm{~h}-10 \mathrm{~h}$ & 4 & $1,6,35$ \\
\hline 12 & EEP & $07 / 11 / 06$ & $12 \mathrm{~h}-13 \mathrm{~h}$ & 3 & $1,2,20$ \\
\hline 13 & EEP & 07/11/06 & $12 \mathrm{~h}-13 \mathrm{~h}$ & 6 & $1,3,8,12,22$ \\
\hline \multirow[t]{2}{*}{14} & EEP & $21 / 11 / 06$ & $9 \mathrm{~h}-10 \mathrm{~h}$ & 9 & $1,2,4,23,24$ \\
\hline & EEP & & $10 \mathrm{~h}-11 \mathrm{~h}$ & 6 & $1,4,13,23$ \\
\hline 15 & EEP & $21 / 11 / 06$ & $12 \mathrm{~h}-13 \mathrm{~h}$ & 2 & 2,13 \\
\hline
\end{tabular}


Continuação da Tabela 4. Continuation of Table IV.

\begin{tabular}{|c|c|c|c|c|c|}
\hline 17 & EEP & $21 / 11 / 06$ & $11 \mathrm{~h}-12 \mathrm{~h}$ & 9 & $1,2,4,25$ \\
\hline 1 & FPB & 06/10/06 & $9 \mathrm{~h}-10 \mathrm{~h}$ & 4 & $1,3,7$ \\
\hline 2 & FPB & $20 / 10 / 06$ & $10 \mathrm{~h}-11 \mathrm{~h}$ & 4 & 1,2 \\
\hline 3 & FPB & 06/10/06 & $10 \mathrm{~h}-11 \mathrm{~h}$ & 4 & 1,3 \\
\hline 4 & FPB & 06/10/06 & $11 \mathrm{~h}-12 \mathrm{~h}$ & 4 & $1,34,26$ \\
\hline 7 & FPB & $20 / 10 / 06$ & $9 \mathrm{~h}-10 \mathrm{~h}$ & 5 & $1,2,27$ \\
\hline 8 & FPB & $20 / 10 / 06$ & $9 \mathrm{~h}-10 \mathrm{~h}$ & 4 & $1,3,28,29$ \\
\hline 14 & FPB & $17 / 11 / 06$ & $9 \mathrm{~h}-10 \mathrm{~h}$ & 7 & $2,3,4,34$ \\
\hline 15 & FPB & $17 / 11 / 06$ & $9 \mathrm{~h}-10 \mathrm{~h}$ & 9 & 3,4 \\
\hline 16 & FPB & $17 / 11 / 06$ & $10 \mathrm{~h}-11 \mathrm{~h}$ & 5 & $3,8,30,11,16$ \\
\hline \multirow[t]{2}{*}{1} & $\mathrm{SC}$ & $03 / 10 / 06$ & $9 \mathrm{~h}-10 \mathrm{~h}$ & 4 & 1,2 \\
\hline & & $18 / 10 / 06$ & $9 \mathrm{~h}-10 \mathrm{~h}$ & 5 & $1,2,32$ \\
\hline \multirow[t]{2}{*}{2} & $\mathrm{SC}$ & $03 / 10 / 06$ & $9 \mathrm{~h}-10 \mathrm{~h}$ & 5 & $1,17,22,31$ \\
\hline & & 18/10/06 & $9 \mathrm{~h}-10 \mathrm{~h}$ & 5 & 1,32 \\
\hline \multirow[t]{2}{*}{3} & $\mathrm{SC}$ & $03 / 10 / 06$ & $10 \mathrm{~h}-11 \mathrm{~h}$ & 6 & 1,2 \\
\hline & & $18 / 10 / 06$ & $11 \mathrm{~h}-12 \mathrm{~h}$ & 2 & 1,2 \\
\hline \multirow[t]{2}{*}{4} & $\mathrm{SC}$ & 03/10/06 & $11 \mathrm{~h}-12 \mathrm{~h}$ & 4 & $1,18,21$ \\
\hline & & $18 / 10 / 06$ & $11 \mathrm{~h}-12 \mathrm{~h}$ & 7 & $1,2,36,37$ \\
\hline \multirow[t]{2}{*}{5} & $\mathrm{SC}$ & 03/10/06 & $11 \mathrm{~h}-12 \mathrm{~h}$ & 13 & $1,2,16,29,38,39$ \\
\hline & & $18 / 10 / 06$ & $11 \mathrm{~h}-12 \mathrm{~h}$ & 9 & $1,2,31,33,36,40$ \\
\hline \multirow[t]{2}{*}{6} & $\mathrm{SC}$ & 03/10/06 & $12 \mathrm{~h}-13 \mathrm{~h}$ & 6 & $1,2,41$ \\
\hline & & $18 / 10 / 06$ & $12 \mathrm{~h}-13 \mathrm{~h}$ & 2 & 2,16 \\
\hline 7 & $\mathrm{SC}$ & 03/10/06 & $12 \mathrm{~h}-13 \mathrm{~h}$ & 12 & 1,2 \\
\hline \multirow[t]{2}{*}{8} & $\mathrm{SC}$ & $18 / 10 / 06$ & $9 \mathrm{~h}-10 \mathrm{~h}$ & 6 & $1,2,14,24$ \\
\hline & & $30 / 10 / 06$ & $9 \mathrm{~h}-10 \mathrm{~h}$ & 5 & 1,2 \\
\hline \multirow[t]{2}{*}{9} & $\mathrm{SC}$ & $18 / 10 / 06$ & $10 \mathrm{~h}-11 \mathrm{~h}$ & 8 & $1,2,16,34$ \\
\hline & & $30 / 10 / 06$ & $9 \mathrm{~h}-10 \mathrm{~h}$ & 4 & $1,2,14$ \\
\hline 10 & $\mathrm{SC}$ & $18 / 10 / 06$ & $12 \mathrm{~h}-13 \mathrm{~h}$ & 9 & $1,2,42$ \\
\hline \multirow[t]{2}{*}{11} & $\mathrm{SC}$ & $30 / 10 / 06$ & $9 \mathrm{~h}-10 \mathrm{~h}$ & 4 & 1,2 \\
\hline & & $10 / 11 / 06$ & $9 \mathrm{~h}-10 \mathrm{~h}$ & 3 & 1,35 \\
\hline \multirow[t]{2}{*}{13} & $\mathrm{SC}$ & $10 / 11 / 06$ & $10 \mathrm{~h}-11 \mathrm{~h}$ & 2 & 41,43 \\
\hline & & $30 / 10 / 06$ & $10 \mathrm{~h}-11 \mathrm{~h}$ & 3 & 1,2 \\
\hline 17 & $\mathrm{SC}$ & $10 / 11 / 06$ & $11 \mathrm{~h}-12 \mathrm{~h}$ & 2 & 1,2 \\
\hline Total & & & & 291 & \\
\hline
\end{tabular}

Espécies de abelhas: 1- Apis mellifera; 2- Scaptotrigona depilis; 3- Scaptotrigona polysticta; 4- Rophitulus sp.; 5- Hylaeus sp.2; 6- Hylaeus sp.5;

7- Melipona quinquefasciata; 8- Melipona rufiventris; 9- Augochloropsis brachycephala; 10- Partamona combinata; 11-Ceratina (Crewella) sp.1; 12- Nannotrigona testaceicornis; 13- Colletes petropolitanus; 14- Augochloropsis aurifluens; 15- Augochloropsis sp.;16- Augochloropsis callichroa; 17- Augochloropsis smithiana; 18- Augochloropsis sp.3; 19-Dialictus sp.; 20-Dialictus sp.4; 21-Dialictus sp.5; 22- Exomalopsis (E.)cfr. tomentosa;

23-Exomalopsis minor; 24- Thectochlora alaris; 25- Hylaeus sp.9; 26-Xylocopa suspecta; 27-Exomalopsis fulvofasciata; 28-Exomalopsis auropilosa; 29- Rhinocorynura crotonis; 30- Cephalotrigona capitata; 31-Geotrigona mombuca; 32- Megachile gracilis; 33- Tropidopedia sp. 1; 34Paratrigona lineata; 35- Trigona spinipes; 36- Temnosoma sp.1; 37- Augochlora sp.6; 38- Augochloropsis brachycephala; 39- Schwarziana mourei; 40- Tetragonisca angustula; 41- Temnosoma cfr. metallicum; 42- Megachile (M.) sp.1; 43- Tetrapedia sp.2. 
linha vertical de cada uma delas, a razão porcentual. $\mathrm{O}$ limite superior calculado para $\mathrm{K}=0$, na primeira etapa, foi 0,20 e o limite inferior de todas as espécies dominantes foi maior que este valor. As espécies estão arranjadas do topo para a base, em ordem decrescente, de acordo com a abundância relativa de cada espécie.

$\mathrm{Na}$ segunda etapa da coleta, foram determinadas dez espécies de abelhas dominantes $(15,15 \%)$ dentre as identificadas (Figura 10). Dessas, sete espécies eram da família Apidae, englobando $382(88,4 \%)$ dos 432 indivíduos desta família. Das outras três espécies dominantes, uma pertencia à família Halictidae, com 14 dos 58 indivíduos desta família; uma à família Colletidae, com seis dos 17 indivíduos desta família; e uma à família Andrenidae, com todos os 42 indivíduos desta família. Na família Megachilidae não apareceram espécies dominantes. Para as dez espécies de abelhas dominantes, o limite inferior foi maior do que 0,53 - valor esse que representa o limite superior para $\mathrm{K}=0$.

\section{ESPÉCIES DE ABELHAS QUE VISITARAM PLANTAS DIFERENTES DE Matayba guianensis}

Algumas espécies de abelhas existentes nas áreas amostradas foram coletadas esporadicamente em outras plantas, em ninhos ou frutos (Tabela 5), para verificar a existência de espécies não atraídas pela $M$. guianensis.

Foram coletadas 19 espécies de abelhas em espécies de plantas sincronopatricas com M. guianensis, nas três áreas de estudo. Dentre estas, nove $(47,4 \%)$ foram coletadas também em $M$. guianensis, enquanto $10(52,6 \%)$ foram observadas somente em outras espécies de plantas (Tabela 5).

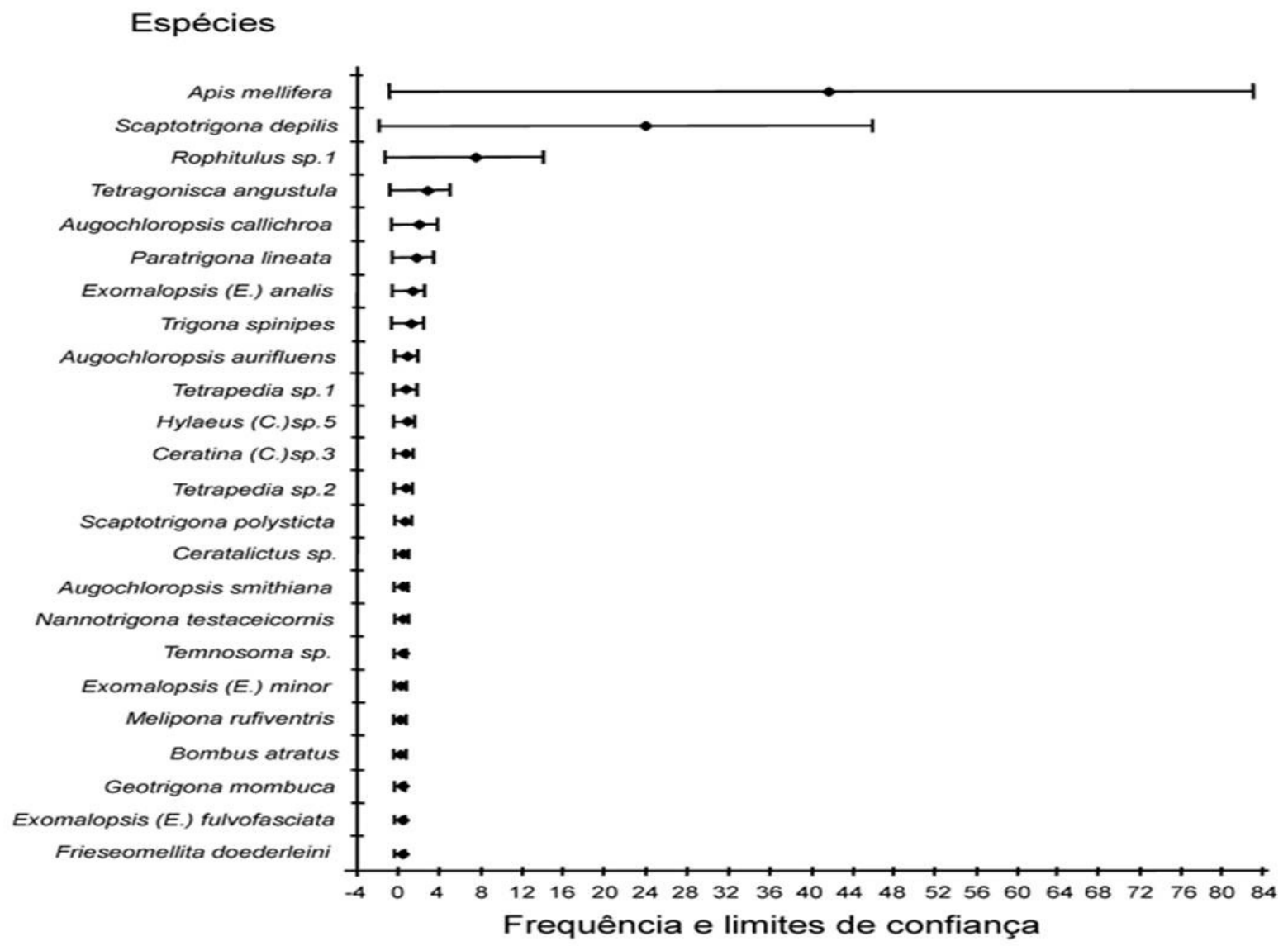

Figura 9. Abundância relativa das espécies dominantes de Apoidea, visualizada pelo método de probabilidade de ocorrência (Kato et al. 1952) com suas respectivas porcentagens de ocorrência e limites de confiança inferior e superior coletadas em Matayba guianensis em áreas de cerrado de Uberlândia, MG. Outubro/2005 a janeiro/2006.

Figure 9. Relative abundance of the Apoidea dominant species, visualized by the probability occurrence method (Kato et al. 1952) with its respective percentages of occurrence and upper and lower confidence limits, sampled on Matayba guianensis in cerrado areas at Uberlândia, Minas Gerais. 


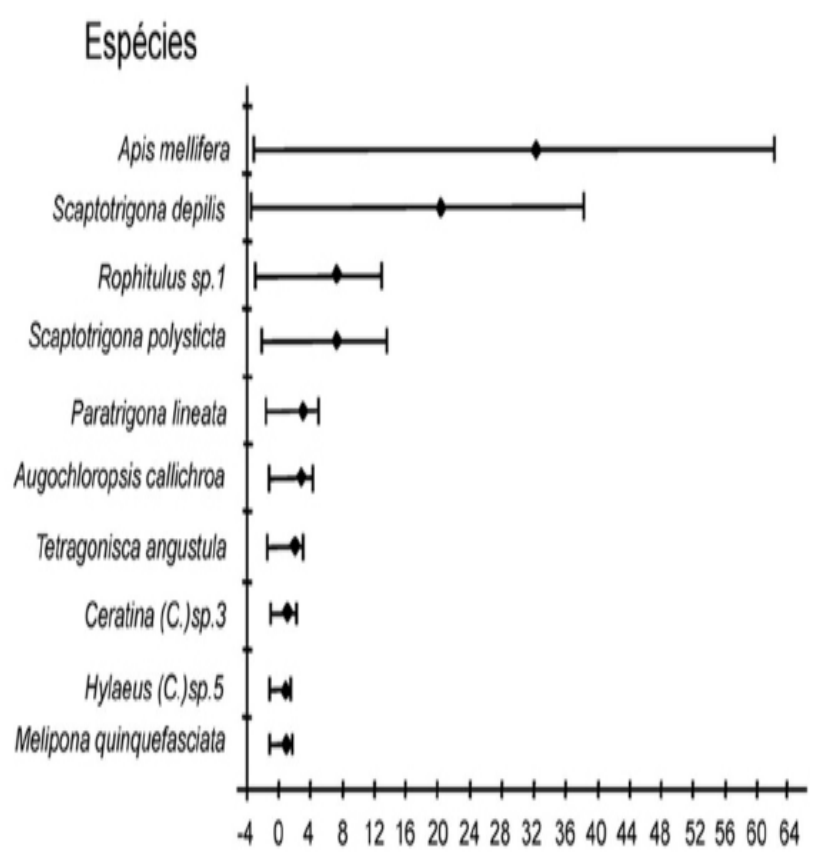

Frequência e limites de confiança

Figura 10. Abundância relativa das espécies dominantes de Apoidea, visualizada pelo método de probabilidade de ocorrência (Kato et al. 1952) com suas porcentagens de ocorrência e limite inferior e superior, coletadas em Matayba guianensis em áreas de cerrado de Uberlândia, MG. Outubro a dezembro/2006.

Figure 10. Relative abundance of the Apoidea dominant species, visualized by the probability occurrence method (Kato et al. 1952) with its respective percentages of occurrence and upper and lower confidence limits, sampled on Matayba guianensis in cerrado areas at Uberlândia, Minas Gerais. October to December/2006.

\section{DISCUSSÃO}

O número de espécies coletadas em diferentes levantamentos de abelhas no mundo varia de oito a 333 e no Brasil, em nove estudos em diversos tipos de vegetação, o número de espécies ficou entre 45, na caatinga, e 212, em jardins abandonados (Williams et al. 2001). Já Pinheiro-Machado et al. (2002) citam que, no Brasil, ocorrem de 35 a mais de 300 espécies num único local. O número de espécies coletado apenas em M. guianensis é, portanto, maior do que as espécies coletadas para muitas comunidades inteiras no Brasil e no mundo.

Atualmente são reconhecidas nove famílias de abelhas, sendo cinco presentes no Brasil (Silveira et al. 2002) e estão todas representadas neste estudo: Andrenidae, Apidae, Colletidae, Halictidae e Megachilidae.

A riqueza das famílias varia de acordo com o tipo de vegetação. Por exemplo, em florestas tropicais úmidas, Halictidae é mais rica que Apidae, seguida por Megachilidae, Colletidae e Andrenidae (Pinheiro-Machado et al. 2002). Já no cerrado, Apidae é a familia com maior riqueza e número de indivíduos (Silveira 1989, Silveira \& Campos 1995, Carvalho \& Bego 1996, Andena et al. 2005, Araújo et al. 2006). Os trabalhos anteriormente citados mostram um padrão geral para o cerrado, com Apidae sendo a família mais rica (considerandose aqui a inclusão de Anthophoridae), seguida de Halictidae e Megachilidae. Colletidae e Andrenidae são representadas por menor número de espécies. Este padrão comunitário se manteve praticamente o mesmo no presente estudo, com uma única espécie de planta amostrada. Apidae foi de longe a família mais rica e abundante. Apenas Megachilidae não seguiu este padrão, pois foi representada por menor número de espécies e de indivíduos do que Colletidae. Assim, pode ser que $M$. guianensis não seja tão atrativa para esta família quanto para as outras.

Outro aspecto interessante é que os gêneros de abelhas mais ricos em espécies, no cerrado, são Megachile, Centris, Epicharis, Paratetrapedia, Augochloropsis, Augochlora, Ceratina e Exomalopsis (Pinheiro-Machado et al. 2002). Desses oito gêneros, sete estiveram representados na amostra, mas não foram capturadas abelhas do gênero Centris visitando M. guianensis e ocorreu apenas um indivíduo do gênero Epicharis. Espécies destes dois gêneros são comuns nas áreas estudadas e foram coletadas visitando Byrsonima intermedia e Caussarea hydrangeaefolia, indicando que $M$. guianensis pode não ser atrativa para essas abelhas. Nos gêneros Epicharis e Centris, as abelhas fêmeas coletam óleo nas flores (Silveira et al 2002) e M. guianensis não oferece tal recurso.

A maior representatividade de Apidae em número de indivíduos se deve principalmente à abundância de A. mellifera e $S$. depilis, as duas espécies dominantes com maior número de indivíduos. A diversidade e abundância das espécies desempenham um papel fundamental na estruturação das comunidades, assim como as espécies-chave e as espécies dominantes. Segundo Krebs (1994), uma função na comunidade pode ser ocupada por uma única espécie, no caso, uma espécie-chave, e a presença dessa função pode ser crítica para a comunidade. Quanto às espécies dominantes, o autor explica que são espécies reconhecidas por sua abundância numérica e biomassa, usualmente definidas separadamente para cada nível 
Tabela 5. Abelhas coletadas em plantas diferentes de Matayba guianensis ou em outros locais, em áreas de cerrados em Uberlândia, MG. Outubro a dezembro/2005 e outubro a dezembro/2006 (EEP: Estação Ecológica do Panga; FPB: cerrado na Fazenda Palma da Babilônia; SC: reserva na Souza Cruz)

Table 5. Bees samples on different Matayba guianensis plants or on other places, in cerrado areas at Uberlândia, MG. October to December/2005 and October to December/2006 (EEP: Panga Ecological Reserve; FPB: cerrado at Fazenda Palma da Babilonia; SC: Souza Cruz Reserve).

\begin{tabular}{|c|c|c|}
\hline Espécie & Planta visitada / outros & Área \\
\hline Apis mellifera Linnaeus, 1758 & Brachyaria decumbens (Poaceae) & EEP \\
\hline Augochloropsis brachycephala Moure, 1943 & Byrsonima intermedia (Malpighiaceae) & EEP \\
\hline Augochloropsis patens (Vachal, 1903) & Brachyaria decumbens (Poaceae) & EEP \\
\hline Bombus atratus Franklin, 1913 & - & FPB \\
\hline Centris (Centris) sp. 1 & Byrsonima intermedia (Malpiguiaceae) & EEP \\
\hline Centris (Centris) spilopoda Moure, 1969 & Caussarea hydrangeafolia (Rubiaceae) & EEP \\
\hline Centris (Ptilopus) denudans Lepetelier, 1840 & 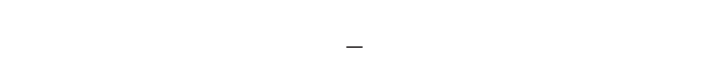 & EEP \\
\hline Epanthidium tigrinum (Schrottky,1905) & No fruto de Pouterea ramiflora (Sapotaceae), no chão. & FPB \\
\hline Epicharis (Epicharitides) cockerelli Friese, 1900 & - & EEP \\
\hline \multirow[t]{3}{*}{ Epicharis (Triepicharis) analis Lepeletier, 1841} & Byrsonima intermedia (Malpighiaceae) & FPB \\
\hline & Caussarea hydrangeaefolia (Rubiaceae) & EEP \\
\hline & Qualea multiflora (Vochysiaceae) & FPB \\
\hline Epicharis iheringi Friese, 1899 & Byrsonima intermedia (Malpighiaceae) & EEP \\
\hline Euglossa sp. & Caussarea hydrangeaefolia (Rubiaceae) & FPB \\
\hline Exomalopsis (Exomalopsis) fulvofasciata Smith, 1879 & Eugenia involucrata (Myrtaceae) & EEP \\
\hline Oxaea flavescens Klug, 1807 & Caussarea hydrangeaefolia (Rubiaceae) & EEP \\
\hline Oxyitrigona tataira (Smith, 1863) & $\begin{array}{c}\text { Coletando "homedew" de cigarrinhas agregadas em } \\
\text { Matayba guianensis }\end{array}$ & FPB \\
\hline Paratetrapedia connexa (Vachal, 1909) & Byrsonima intermedia (Malpighiaceae) & EEP \\
\hline Paratrigona lineata (Lepeletier, 1836) & Caussarea hydrangeaefolia (Rubiaceae) & FPB \\
\hline Trigona hyalinata (Lepeletier, 1836) & Ninho em parede & $\mathrm{SC}$ \\
\hline Trigona spinipes (Fabricius, 1793) & Eugenia involucrata (Myrtaceae) & EEP \\
\hline
\end{tabular}

trófico e que exercem um poderoso controle sobre a ocorrência de outras espécies.

Quanto às duas espécies mais abundantes, $A$. mellifera e $S$. depilis, A. mellifera é uma abelha eussocial, de tamanho médio, ocorrendo em todo o Brasil, representada por híbridos de várias subespécies européias e uma subespécie africana (Silveira et al. 2002). Possuem colônias perenes, grandes populações, área de forrageamento extensa, alta capacidade de comunicação e orientação, forrageando em grupos. É uma espécie generalista, utilizando-se de uma grande variedade de plantas para coleta de pólen e néctar e também oportunista, ou seja, capaz de selecionar os recursos alimentares mais proveitosos (Lorenzon et al. 2003).

Em plantas de $M$. guianensis com muitas flores atrativas, A. mellifera praticamente monopolizava todo o recurso floral, com inúmeras operárias forrageando ao mesmo tempo. No final da floração, quando os recursos estavam mais escassos e as flores mais velhas, foram coletadas em menor número. Tal comportamento oportunista das abelhas africanizadas é ressaltado em estudos com flora e fauna apícola da caatinga, onde foi observada a dominância de suas operárias na exploração de algumas espécies de plantas que se encontravam agrupadas e em alta densidade (Lorenzon et al. 2003).

Se A. mellifera fosse excluída da amostra, como fazem alguns autores (ex. Araújo et al. 2006), o total de abelhas coletadas passaria de 2078 para 1260 . No entanto, A. mellifera é de fundamental importância na estruturação das comunidades tropicais, representando um potencial impacto ecológico sobre as abelhas nativas, como resultado da competição por recursos alimentares (Aguiar et al. 2002). O aumento na dominância de abelhas melíferas corresponde a um declínio na visitação total das flores e conduz a uma redução na diversidade de polinizadores (Roubik 1996, Kearns et al. 1998). Com milhares de colônias de A. mellifera coexistindo com abelhas nativas, é 
impossível imaginar que não ocorram alterações nas interações intraespecíficas (Biesmeijer \& Slaa 2006). Por exemplo, em áreas de savana na Guiana Francesa, A. mellifera deslocou completamente Melipona favosa e M. fulva para flores mais próximas de áreas abertas (Roubik 1996). Apesar destas influências, há poucas evidências de que o domínio de A. mellifera possa causar extinção local ou regional de espécies com as quais competem por recursos (Kremen \& Ricketts 2000). Por exemplo, em estudos com a abundância das abelhas nativas no Panamá, antes e depois da invasão das abelhas melíferas, não foi encontrado declínio em nenhuma espécie de abelha indígena (Roubik \& Wolda 2001).

Scaptotrigona depilis é uma abelha sem ferrão, que nidifica em ocos de troncos de árvores (Martins et al. 2004) . Forrageia em grupo e as forrageiras comunicam a fonte de alimento para as outras por meio de trilhas de cheiro desde o alimento até o ninho, com grande precisão; além disso, colocam também marcas químicas adicionais na fonte de alimento (Schmidt et al. 2003, Jarau et al. 2003). Em experimentos com abelhas $S$. mexicana, essas se mostraram capazes de encontrar a fonte de alimento a uma distância e direção específica com grande precisão (Sanchez et al. 2004). No Brasil, S. depilis ocorre em MG, MS, PR, RS e SP (Silveira et al. 2002).

A abundância de $A$. mellifera e $S$. depilis em relação às outras espécies poderia ser parcialmente explicada pelo modo de vida eussocial, com colônias geralmente populosas, ativas durante todo o ano e que forrageiam em grupo. Assim, uma espécie eussocial seria o equivalente ecológico de várias espécies solitárias (Michener 1979).

Por outro lado, Biesmeijer \& Slaa (2006) argumentam que as abelhas sem ferrão poderiam estar aumentando sua especialização em alguns recursos florais como forma de responder à chegada da abelha africanizada. Deste modo, o grande número de visitas de $S$. depilis às flores de $M$. guianensis pode ser indicativo de uma preferência dessa abelha à planta.

Uma das explicações para a abundância de $A$. mellifera na SC seria a presença de colméias na reserva, segundo funcionários da fábrica. A. mellifera não requer local específico para o estabelecimento de colônias, pois constrói ninhos externos (Silva-Pereira \& Santos 2006). Outra explicação seria a própria localização do cerrado, dentro da zona urbana, onde a vegetação é escassa. Num entorno de $2 \mathrm{~km}$ de um ponto central dessa reserva, existem apenas 9,73\% de vegetação natural. Assim, para espécies generalistas, oportunistas e cosmopolitas como $A$. mellifera, tais fragmentos de vegetação dentro de zona urbana serviriam como um refúgio ideal. Além da localização, o tamanho do cerrado pode estar influenciando nesta predominância. Em pequenos fragmentos de floresta, em Chaco Serrano, a fauna de insetos visitantes florais é incrivelmente dominada pela abelha exótica $A$. mellifera (Aizen \& Feisinger 1994a, 1994b). O mesmo pode estar acontecendo em pequenos fragmentos de cerrado.

A terceira espécie dominante mais abundante, Rophitulus sp., foi a única espécie da família Andrenidae coletada. A exemplo das espécies desta família, as abelhas do gênero Rophitulus nidificam no solo (Silveira et al. 2002). O gênero Rophitulus é um grupo bastante heterogêneo, com grande número de espécies novas, principalmente em São Paulo, Paraná e Minas Gerais, sendo descritas apenas três espécies para MG: $R$. anomalus, $R$. friesei e $R$. solani (Silveira et al. 2002). Abelhas do gênero Rophitulus sp. não haviam sido coletadas em trabalhos anteriores no município de Uberlândia (Carvalho \& Bego 1995, 1996, 1997) e esta pode ser uma espécie nova. Dada a abundância com que foi encontrada nesse estudo, parece ser uma espécie bastante adaptada aos cerrados mais conservados da região, pois praticamente não foi coletada na SC, dentro da zona urbana. Sendo uma espécie que não forrageia em grupo, uma explicação para sua abundância é que talvez seja particularmente atraída pelas flores de $M$. guianensis, o que também é evidenciado pelo fato da espécie não ter sido coletada em outras plantas.

Além das três espécies mais abundantes, $M$. guianensis atraiu uma numerosa guilda de abelhas. Em inventários de abelhas nos cerrados do Brasil, em um ano de coleta, encontrou-se 103 espécies de abelhas no cerrado de Corumbataí, SP (Andena et al. 2005), 183 espécies em Paraopeba, MG (Silveira 1989), 128 espécies em Uberlândia, MG (Carvalho \& Bego 1995, 1996, 1997), 91 espécies em Ouro Preto, MG (Araújo et al. 2006). Em três anos de coleta, também no cerrado de Corumbataí, SP, Campos (1989) coletou 117 espécies. Em todos esses trabalhos, as abelhas foram coletadas em várias plantas diferentes e por períodos de tempo mais longo. 
Coletas em uma única espécie de planta supostamente deveriam refletir menos a comunidade total de abelhas de uma área onde há múltiplas e abundantes flores. Entretanto, onde há poucas flores dominantes, as coletas em uma única espécie podem dar uma razoável aproximação da totalidade de espécies de abelhas (Williams et al. 2001). No caso específico do cerrado, existem flores o ano todo e as abelhas mudam sua preferência alimentar de acordo com as diversas floradas e os recursos oferecidos pela planta. Assim, na época da floração de M. guianensis existiam nas três áreas várias outras plantas atrativas sendo visitadas por diferentes espécies de abelhas. Algumas dessas espécies visitaram também a $M$. guianensis, mas outras não, indicando que a guilda de visitantes é apenas parte da riqueza de abelhas nas áreas estudadas.

De qualquer forma, a coleta de 105 espécies de abelhas em uma única espécie de planta, é um dado relevante e significativo, capaz de representar boa parte das espécies existentes nas áreas estudadas. Ainda mais, considerando-se que a média do número de espécies de abelhas coletadas em várias plantas do cerrado foi de 124,4 espécies, conforme os cinco trabalhos anteriormente citados.

Coletas focadas em uma única planta ou grupo de plantas atrativas podem representar parcelas significativas da fauna de abelhas de uma determinada área (conferir Minkley et al. 1999, Macedo \& Martins 1999, Harter et al. 2002, Ramalho \& Silva 2002, Moeller 2004).

Estudos incluindo todas as plantas de uma determinada área mostram mais espécies e indivíduos de abelhas (em média, 106,6 espécies) do que estudos com coleta com uma só planta (em média, 19,6 espécies) (Williams et al. 2001). No entanto, no presente estudo, o número de espécies de abelhas em uma só planta foi muito maior, indicando que $M$. guianensis é especialmente atrativa para as abelhas. Além disso, ela foi a espécie mais atrativa em 75 espécies de plantas amostradas na EEP em 1988 e 1989 (Carvalho \& Bego 1997). É possível argumentar que os cerrados amostrados devem ser áreas ricas em abelhas e que a metodologia utilizada, amostrandose duas floradas consecutivas de $M$. guianensis, tenha sido particularmente eficiente.

Os dados de coleta em uma só planta, mesmo que não representem a comunidade como um todo, são encorajadores porque podem capturar a essência da variação da comunidade de abelhas, no tempo e no espaço (F.A. Silveira resultados não publicados). A proporção de todas as espécies de abelhas coletadas em toda a flora não difere da coletada em uma única espécie de planta, sugerindo que as espécies raras de abelhas se distribuem homogeneamente entre as espécies de plantas (Williams et al. 2001). Ou seja, mesmo a coleta se restringindo a uma dada espécie de planta, esta deverá ser visitada pela mesma proporção de espécies de abelhas dominantes e raras, que visitam a totalidade das plantas amostradas de um dado local. Outro ponto importante é que, ao comparar a fauna de abelhas coletada em flores de áreas diferentes, o espectro de abelhas pode ser influenciado pelas diferenças florísticas entre as áreas. $\mathrm{O}$ uso de uma planta focal particularmente atrativa como M. guianensis poderia permitir uma avaliação mais precisa das mudanças faunísticas entre áreas diferentes.

Quando as abelhas se distribuem entre as plantas de M. guianensis, utilizam os mesmos recursos florais, pólen e néctar, o que pode acarretar partição de recursos ou competição pelo alimento, causada pela sobreposição de nichos. A maior abundância das três espécies de abelhas dominantes coletadas em maior número, A. mellifera, S. depilis e Rhophitulus sp, coincidiu com o pico de floração de M. guianensis, mostrando que estas espécies visitam a planta ao mesmo tempo.

A coexistência de espécies de abelhas em uma mesma planta, utilizando diferentes estratégias de forrageamento, é descrita por vários autores (Johnson \& Hubbel 1974, Dutra \& Machado 2001, Morgado et al. 2002, El Shafie \& Mogga 2002). Outros relatam comportamentos agressivos entre as abelhas. Em algumas espécies, tendências agressivas são regularmente expressadas, na forma de ataque um a um, sendo que o indivíduo atacado se move para outra flor (Frankie 1976). Há também autores que sugerem competição entre certas espécies, como entre $T$. angustula e $P$. lineata e entre $T$. spinipes e $S$. postica, espécies com maior sobreposição de nicho e de tamanho corporal semelhante (Nogueira-Ferreira \& Augusto 2007).

Tais comportamentos de forrageamento, envolvendo partição de recursos e/ou competição, podem ser mais bem entendidos por meio dos dados 
de coleta de espécies de abelhas em uma mesma planta, no mesmo horário. Abelhas pequenas, como Partamona, Nannotrigona e Tetragonisca, tendem a ser mais numerosas em uma planta quando as espécies agressivas não estão presentes (Biesmeijer \& Slaa 2006). Esses autores, na revisão de 28 estudos com abelhas sociais, destacaram dois grupos principais de forrageiras: as abelhas de tamanho médio e não agressivas e as agressivas, tais como A. mellifera e $T$. spinipes.

No presente estudo, abelhas grandes e comuns no cerrado, como Epicharis analis e Bombus morio estiveram ausentes na amostra. Outras foram pouco representadas, como B. atratus. As espécies de abelhas visitantes de $M$. guianensis são essencialmente abelhas de tamanho pequeno (menos de $12 \mathrm{~mm}$ ), com poucas espécies de tamanho médio a grande (mais de $12 \mathrm{~mm})$.

Uma das explicações para a pouca representatividade de abelhas grandes na amostra é o próprio tamanho corporal da abelha, que poderia dificultar o pouso e a movimentação nas flores pequenas de M. guiansensis. Abelhas de porte maior, como Xylocopa frontalis, X. grisescens, Bombus morio e $B$. atratus apresentaram dificuldades para pousarem nas flores de Solanum palinacanthum (Solanaceae), utilizando as asas para se equilibrarem (Carvalho et al. 2001).

Em todos os horários nos quais foram capturadas abelhas pequenas, nas plantas marcadas, A. mellifera estava presente. É de se supor então que tais abelhas pequenas possuam estratégias que as permitam explorar os mesmos recursos que abelhas agressivas. Por exemplo, $N$. testaceicornis é hábil em encontrar rapidamente fontes de alimento e em deixar uma fonte quando espécies agressivas chegam, retornando quando elas saem (Beismeijer \& Slaa 2006).

Há várias estratégias de divisão de recursos. Algumas espécies de abelhas têm um nicho de forrageamento mais amplo e outras, mais estreito (Biesmeijer \& Slaa 2006). Outras, podem dividir os recursos florais: forrageando em diferentes tempos da estação, em diferentes tempos do dia (partição temporal) ou se concentrando em diferentes espécies de flores (Ginsberg 1983). B. morio apresentou maior atividade forrageadora no início e final da tarde, diferentemente de outras espécies (Dutra \& Machado 2001). A. mellifera sudanensis e A. florea coletam pólen nas mesmas plantas, mas a primeira coleta cedo na manhã e no final da tarde, enquanto $A$. florea começa a coleta mais tarde na manhã e termina mais cedo à tarde (El Shafie \& Moga 2002).

Conforme em trabalhos anteriormente citados, as visitas das abelhas à M. guianensis, de um modo geral, aconteceram durante todo o horário de coleta, mas com alguns picos diferentes de atividade entre as espécies, como em A. mellifera e $S$. depilis. No entanto, como as correlações não foram significativas, não é possível afirmar que existe uma relação entre o aumento no número de indivíduos de uma espécie e diminuição da outra, o que poderia indicar mais partição de recursos que competição.

Outra estratégia de forrageamento para evitar competição seria visitar plantas pistiladas e plantas estaminadas em diferentes horários e graus de intensidade. Embora abelhas tenham demonstrado preferência por plantas estaminadas em arbustos de Hebe stricta, as diferentes espécies de polinizadores respondem diferentemente aos dois morfos da planta (Delph \& Lively, 1992). Estudos mais detalhados da biologia floral de $M$. guianensis poderiam indicar preferências na visitação de acordo com o sexo da planta, já que em $M$. guianensis existem plantas estaminadas, plantas pistiladas e plantas pistiladas e estaminadas. A maior proporção de visitas de abelhas às plantas estaminadas aconteceu devido à própria preponderância destas na população amostrada, não sendo possível afirmar que havia preferência por um ou outro tipo floral.

A visitação em flores mais novas e em flores mais velhas também poderia funcionar como uma estratégia para partição de recursos. Por exemplo, A. mellifera se mostrou oportunista, visitando intensamente as flores de $M$. guianensis quando o recurso era rico e praticamente desaparecendo quando as flores estavam escassas ou velhas. Nessa ocasião, as flores eram predominantemente visitadas por abelhas Halictidae, do gênero Augochlora e Augochloropsis.

É importante notar que todas as abelhas coletadas visitando as flores de $M$. guianensis podem funcionar como polinizadores efetivos, especialmente nas plantas com ambos os tipos florais. Na verdade, as flores de M. guianensis são generalistas e podem ser incluídas no grupo de espécies de cerrado polinizadas por pequenos insetos, que não apresentam restrições aos tipos de polinizadores, sendo polinizadas por 
abelhas, dípteros, vespas e outros pequenos insetos (Oliveira \& Gibbs 2000).

Finalizando, um padrão que parece existir nas comunidades de abelhas é que existem poucas espécies com grande número de indivíduos $\mathrm{e}$ muitas espécies com poucos indivíduos (PinheiroMachado et al. 2002). Assim, nesse aspecto, a estrutura da guilda de abelhas visitantes de $M$. guianensis, mostrou-se condizente com o padrão de outras guildas e comunidades de abelhas. Também a proporção das famílias em número de espécies e indivíduos, com exceção de Megachilidae, seguiu o padrão encontrado em outros trabalhos realizados no cerrado. As 105 espécies de abelhas coletadas em M. guianensis representam uma boa amostragem das espécies de abelhas como um todo, que forrageiam nas diversas plantas dos cerrados amostrados. Portanto, M. guianensis desempenha um importante papel ecológico como planta fornecedora de recursos para um grande número de indivíduos e de espécies de abelhas do cerrado.

AGRADECIMENTOS: Agradecemos a Fernando Antônio Silveira, do Instituto de Biologia da UFMG, e a Silvia R. M. Pedro, do Departamento de Biologia da FFCLRP- USP, pela identificação das abelhas, sem a qual não teria sido possível a realização deste trabalho.

\section{REFERÊNCIAS}

AGUIAR, C.M.L.; MONTEIRO, V.M.; SANTOS, J.R.R.; FRANÇA, F. \& MELO, E. 2002. Plantas visitadas por Apis mellifera L. (Hymenoptera, Apidae) em uma área de caatinga em Itatim, Bahia, Brasil. Scientibus, Série Ciências Biológicas, 2(1/2): 29-33.

AIZEN, M.A. \& FEISINGER, P. 1994a. Forest fragmentation, pollination, and plant reproduction in a chaco dry forest, Argentina. Ecology, 75(3): 330-350.

AIZEN, M.A. \& FEISINGER, P. 1994b. Habitat fragmentation, native insect pollinators, and feral honey bees in argentine "Chaco Serrano". Ecological Applications, 4 (2): 378-392.

ANDENA, S.R.; BEGO, L.R. \& MECHI, M.R. 2005. A comunidade de abelhas (Hymenoptera, Apoidea) de uma área de cerrado (Corumbataí, SP) e suas visitas às flores. Revista Brasileira de Zoociências, 7(1): 55-91.
ANTONINI, Y. \& MARTINS, R.P. 2003. The value of a tree species (Caryocar brasiliense) for a stingless bee Melipona quadrifasciata quadrifasciata. 2003. Journal of Insect Conservation, 7(1): 167-174

ARAÚJO, G.M. 2006. Uberlândia tem menos de 8\% de cerrado. Correio de Uberlândia, 2/03/2006. Caderno B, p. 2.

ARAÚJO, G.M.; NUNES, J.T.; ROSA, A.G. \& REZENDE, E.J. 1997. Estrutura comunitária de vinte áreas de cerrados residuais no município de Uberlândia, MG. Daphne, 7(2): 7-14.

ARAÚJO, V.A.; ANTONINI, Y. \& ARAÚJO, A.P.A. 2006. Diversity of bees and their floral resources at altitudinal areas in the Southern Espinhaço Range, Minas Gerais, Brasil. Neotropical Entomology, 35(1): 30-40.

BIESMEIJER, J.C.; RICHTER, J.A.P.; SMEETS, M.A.J.P. \& SOMEIJER, M.J. 1999. Niche diferenciation in nectarcolleting stingless bees- the influence of morphology, floral choice and interference competition. Ecological Entomology, 24(4): $380-388$

BIESMEIJER, J.C. \& SLAA, E.J. 2006. The structure of eusocial bee assemblages in Brazil. Apidologie, 37(1): 240-258.

CAMPOS, M.J.O. 1989. Estudo das interações entre a comunidade de Apoidea, na procura de recursos alimentares e a vegetação de cerrado da Reserva de Corumbataí, S.P. Tese de Doutorado. Universidade Federal de São Carlos. São Carlos, SP, Brasil. 114p.

CARVALHO, A.M.C. \& BEGO, L.R. 1995. Seasonality of dominant species of bees in the Panga Ecological Reserve, cerrado, Uberlândia, M G. Anais da Sociedade Entomológica do Brasil, 24(2): 329-337.

CARVALHO, A.M.C. \& BEGO, L.R. 1996. Studies on Apoidea fauna of bees in the Panga Ecological Reserve, Uberlândia, MG. Revista Brasileira de Entomologia, 40(2): 147-156.

CARVALHO, A.M.C. \& BEGO, L.R. 1997. Exploitation of available resources by bee fauna (Apoidea-Hymenoptera) in the Reserva Ecológica do Panga, Uberlândia, state of Minas Gerais, Brazil. Revista Brasileira de Entomologia, 41(1): 101-107.

CARVALHO, C.A.L.; MARQUES, O.M.; VIDAL, C.A. \& NEVES, A.M.S. 2001. Comportamento forrageiro de abelhas (Hymenoptera, Apoidea) em flores de Solanum palinacanthum Dunal (Solanaceae). Revista Brasileira de Zoociências, 3(1): 35-44. 
DELPH, L.F. \& LIVELY, C.M. 1992. Pollinator visitation, floral display and nectar production of the sexual morphs of a gynodioecious shrub. Oikos, 63(2): 161-170.

DUPONT, Y.L.; HANSEN, D.M.; VALIDO, A. \& OLESEN, J.M. 2004. Impact of introduced honey bees on native pollinators interactions of the endemic Echium wildpretii (Boraginaceae) on Tenerife, Canary Islands. Biological Conservation, 13(3): 301-311.

DUTRA, J.C.S. \& MACHADO, V.L.L. 2001. Flowering entomofauna in Stenolobium stans (Juss.) Sern (Bignoniaceae). Neotropical Entomology, 30(1): 43-53.

EL SHAFIE, H.AF. \& MOGGA, J.B.B. 2002. Studies on the possible competition for pollen between the honey bee Apis mellifera sudanensis and the imported dwarf honey bee Apis florea (Hymenoptera, Apidae) in North-Khartoum (Sudan). The Basedow Journal of Applied Entomology, 126(10): 557-562.

FERNANDES, C.X. 2005. Estrutura da população de Matayba guianensis Aubl. (Sapindaceae) em uma área de regeneração natural no Parque Victorio Siquierolli (Uberlândia, MG). Monografia de Bacharelado. Universidade Federal de Uberlândia. Uberlândia, MG, Brasil. 15p.

FRANKIE, G.W. 1976. Pollination of widely dispersed trees by animals in Central America, with an emphasis on bee pollination systems. Tropical trees: variation, breeding and conservation, 1: $151-159$.

GINSBERG, H.S. 1983. Foraging ecology bees in an old field. Ecology, 64(1): 165-175.

HARTER, B.; LEISTIKOWC, C.; WILMS, W.; TRUYLIO, B. \& ENGELS, W. 2002. Bees collecting pollen from flowers with poricidal anthers in a south Brazilian Araucaria forest community study. Journal of Apicultural Research, 41(1-2): 9-16.

JARAU, S.; HRNCIR, M.; SCHMIDT, V. M.; ZUCCHI, R. \& BARTH, F. G. 2003. Effectiveness of recruitment behavior in stingless bees (Apidae, Meliponini). Insectes Sociaux, 50(4): 365-374.

JOHNSON, L.K. \& HUBBEL, S.P. 1974. Aggression and competition among stingless bees: field studies. Ecology, 55(1): 120-127.

JONES, M.; MANDELIK, Y. \& DAYAN, T. 2001. Coexistence of temporally partitioned spiny mice: roles of habitat structure and foraging behavior. Ecology, 82(8): 2164-2176.
KATO, M.; MATSUMUDA, T. \& YAMASITA, Z. 1952. Associate ecology of insects found in the paddy field cultivated by various planting forms. Science Reports of the Tôhoku University Fourth Series (Biology), 19(4): 291-301.

KEARNS, C.A.; INOUYE, D.W. \& WASER, N.W. 1998. Endangered mutualisms: the conservation of plant-pollinator interactions. Annual Review of Ecology and Systematics, 29: 83-112.

KREBS, C.J. 1994. Ecology. Harper Collins, New York. 593p.

KREMEN, C. \& RICKETTS, T. 2000. Global perspectives on pollination disruptions. Conservation Biology, 14(5): 1226-1233.

LORENZON, M.C.A.; MATRANGOLO, C.A.R. \& SCHOEREDER, J.H. 2003. Flora visitada pelas abelhas eussociais (Hymenoptera, Apidae) na serra da Capivara, em caatinga no sul do Piaui. Neotropical Entomology, 32(1): 027-036.

MACEDO, J.F. \& MARTINS, R.P. 1999. A estrutura da guilda de abelhas e vespas visitantes florais de Waltheria americana L (Sterculaceae). Anais da Sociedade Entomológica do Brasil, 28(4): 617-633.

MANTOVANI, M.; RUSCHEL, A.R.; REIS, M.S.; PUCHALSKI, A. \& NODARI, R.O. 2003. Fenologia reprodutiva de espécies arbóreas em uma formação secundária da Floresta Atlântica. Revista Árvore, 27(4): 451-458.

MARTINS, C.F.; CORTOPASSI-LAURINO, M.; KOEDAM, D. \& IMPERATRIZ-FONSECA,V.L. 2004. Espécies arbóreas utilizadas para nidificação por abelhas sem ferrão na caatinga (Seridó, PB; João Câmara, RN). Biota Neotropica, 4 (2). <http:// www.biotaneotropica.org.br/v4n2/pt/download?article+BN0010 4022004+item>. (Acesso em 20/11/2008).

MARTINS, E.O. 2002. Biologia floral de Matayba guianensis Aubl. (Sapindaceae) no cerrado de Uberlândia- MG. Monografia de Bacharelado. Universidade Federal de Uberlândia. Uberlândia, MG, Brasil. 92p.

MICHENER, C.D. 1979. Biogeography of the bees. Annals of the Missouri Botanical Garden, 66(3): 277-347.

MINCKLEY, R.L.; CANE, J.H.; KERVIN, L. \& ROULSTON, T. 1999. Spatial predictability and resource of bees (Hym: Apoidea) at a superabundant, widespread resource. Biological Journal of the Linneau Society, 67(1): 119-147. 
MOELLER, D.A. 2004. Pollinator community structure and sources of spatial variation in plant-pollinator interactions in Clarkia xantiana ssp xantiana. Oecologia, 142(1): 1432-1939.

MORGADO, L.N; CARVALHO, C.F.; SOUZA, B. \& SANTANA, M.P. 2002. Fauna de abelhas (Hymenoptera: Apoidea) nas flores de girassol Helianthus annus L. em Lavras-MG. Ciência Agrotécnica, Lavras, 26(6): 1167-1177.

NOGUEIRA-FERREIRA， F.H. \& AUGUSTO, S.C. 2007. Amplitude de nicho e similaridade no uso de recursos florais por abelhas eussociais em uma área de cerrado. Bioscience Journal, 23(1): 45-51.

OLIVEIRA, P.E. \& GIBBS, P.E. 2000. Reproductive biology of woody plants in a cerrado community of Central Brazil. Flora 195: 311-329.

OLIVEIRA, T.V.S.; RANAL, M.A. \& SANTANA, D.G. 2003. Emergência de plântulas de Matayba guianensis Aubl (Sapindaceae) ocorrentes no município de Araquari- MG. Informativo Abrates, 13(3): 337.

PINHEIRO-MACHADO, C.; ALVES-DOS-SANTOS, I; IMPERATRIZ-FONSECA, V.L.; KLEINERT, A.M.F., SILVEIRA, F.A. 2002. Brazilian bee surveys: state of knowledge, conservation and sustainable use. Pp. 115-130. In: P.G. Kevan \& V.L. Imperatriz-Fonseca (eds.). Pollinating bees: the conservation link between agriculture and nature. Ministério do Meio Ambiente, Brasília, DF. 313p.

RAMALHO, S. \& SILVA, M. 2002. Flora oleífera e sua guilda de abelhas em uma comunidade de restinga tropical. Scientibus, Série Ciências Biológicas, 2(1/2): 34-43.

REITZ, R. 1980. Flora Ilustrada Catarinense- Sapindáceas. Herbário Barbosa Rodrigues, Itajaí, SC. 156p.

ROSA, R.; LIMA, S.C. \& ASSUNÇÃO, W.L. 1991. Abordagem preliminar das condições climáticas de Uberlândia, M.G. Sociedade \& Natureza, 3(5/6): 91-108.

ROUBIK, D. W. 1996. African honeybee as exotic pollinators in French Guiana. Pp. 173-182. In: A. Matheson, S.L. Buchmamm, C.O. Toole, P. Westrich \& I.H. Willians (eds.). The conservation of bees. Academic Press, London. 254p.
ROUBIK, D.W. \& WOLDA, H. 2001. Do competing honeybees matter? Dynamics and abundance of native bees before and after a honeybee invasion. Population Ecology, 2(1): 97-111.

SAKAGAMI, S.F.; LAROCA, S. \& MOURE, J.S. 1967. Wild bee biocenotics in São José dos Pinhais (PR) South Brazil: preliminary report. Journal of the Faculty of Science, Hokkaido University Serie G Zoology, 18(1): 57-127.

SANCHEZ, D.; NIEH, J. C.; HÉNAUT, Y.; CRUZ, L. \& VANDAME, R. High precision during food recruitment of experienced(reactivated)foragersinthestingless beeScaptotrigona mexicana (Apidae, Meliponini). Naturwissenschaften, 91(7): 346-349

SCHIAVINI, I. \& ARAÚJO, G.M. 1989. Considerações sobre a vegetação da Reserva Ecológica do Panga (Uberlândia). Sociedade \& Natureza, 1(1): 61-66.

SCHMIDT, V.M.; ZUCCHI, R. \& BARTH, F.G. 2003. A stingless bee marks the feeding site in addition to the scent path (Scaptotrigona aff. depilis). Apidologie, 34(1): 237-248.

SILVA-PEREIRA, V. \& SANTOS, G.M.M. 2006. Diversity in bee (Hymenoptera: Apoidea) and social wasp (hymenoptera: Vespidae, Polistinae) community in Campos Rupestres, Bahia, Brazil. Neotropical Entomology, 35(2): 165-174.

SILVEIRA, F.A. 1989. A fauna de abelhas silvestres e suas fontes de alimento no cerrado de Paraopeba, M. G. Dissertação de Mestrado. Universidade Federal de Viçosa. Viçosa, MG, Brasil. $51 \mathrm{p}$.

SILVEIRA, F.A.; MELO, G.A.R. \& ALMEIDA, E.A.B. 2002. Abelhas brasileiras: sistemática e identificação. Fundação Araucária, Belo Horizonte, MG. 253p.

SILVEIRA, F.A. \& CAMPOS, M.J.O. 1995. A melissofauna de Corumbataí (SP) e Paraopeba (MG) e uma análise biogeográfica das abelhas do cerrado brasileiro (Hymenoptera: Apoidea). Revista Brasileira de Entomologia, 39(2): 371-401.

YAMAMOTO, M. 2009. Polinizadores do maracujá-amarelo (Passiflora edulis f. flavicarpa Deneger, Passifloraceae): riqueza de espécies, freqüência de visitas e a conservação de áreas naturais. Tese de doutorado. Universidade Federal de Uberlândia. Uberlândia, MG, Brasil. 142p. 
WILLIAMS, N.M.; MINCKLEY, R.L. \& SILVEIRA, F.A. 2001.

Variation in native bee fauna and its implication for detecting community changes. Conservation Ecology, 5. <http://www. consecol.org/vol5/iss1/art7/>. (Acesso em 25/11/2008).

Submetido em 31/03/2009

Aceito em 05/12/2009 